\title{
Analysis of Surfactants in Environmental Samples by Chromatographic Techniques
}

\author{
Juan M. Traverso-Soto, Eduardo González-Mazo and Pablo A. Lara-Martín
}

Additional information is available at the end of the chapter

http://dx.doi.org/10.5772/48475

\section{Introduction}

Synthetic surfactants are among the most produced and used organic compounds worldwide. They are a wide range of chemicals characterized by their amphiphilic nature. Thus, their molecules consist of an hydrophilic / polar head group (either charged or uncharged) and an hydrophobic / nonpolar hydrocarbon tail. As a consequence, surfactants show solubility in polar and nonpolar liquids, ability to form micelles, adsorption to phase boundaries and reduction of the surface tension of water. They are economically important due to their specific properties that allow using them as washing, wetting, emulsifying and dispersing agents. Therefore, surfactants are mainly used in the formulation of detergents, personal care products, paints, textiles, pesticide formulations, pharmaceutical, and many other products [1,2]. Many different types of these compounds have been synthesized, although they can be classified into three main groups according to their charge: (1) anionics, (2) non-ionics, and (3) cationics (Figure 1); the first and second groups accounting for the highest production volumes. Thus, the European Committee of Organic Surfactants and their Intermediates (CESIO) reported a production of $1200 \mathrm{ktons}$ of anionic and 1400 ktons of non-ionic surfactants in Europe in 2010, which represents $90 \%$ of the total European production of surfactants.

Linear alkylbenzene sulfonates (LAS), alkyl ethoxysulfates (AES) and alkyl sulfates (AS) are the most widely used anionic surfactants. LAS are commercially available as a mixture containing homologues with alkyl chains ranging from 10 to 14 carbon units, and isomers resulting from the different attachment positions of the phenyl group along that chain (Figure 1a). The chemical structure of AS comprises a $\mathrm{C}_{12-16}$ alkyl chain with a terminal sulfate group. AES share the same structure than AS but they also have a variable number of ethylene oxide (EO) units (Figure 1b). All these compounds are commonly employed in household and laundry detergents, hand dishwashing liquids, shampoos, and other 
(a) LAS

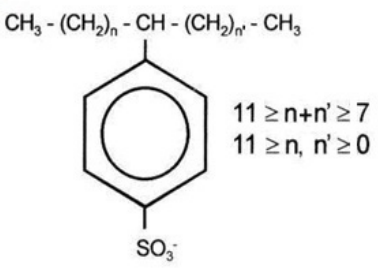

(b) AS, AES

$\mathrm{CH}_{3}-\left(\mathrm{CH}_{2}\right)_{\mathrm{n}}-\left(\mathrm{O}-\mathrm{CH}_{2}-\mathrm{CH}_{2}\right)_{\mathrm{r}^{-}}-\mathrm{O}-\mathrm{SO}_{3}^{-}$
$12 \leq \mathrm{n} \leq 16$
$0 \leq \mathrm{n}^{\prime} \leq 12$

(c) AEOs

$$
\begin{aligned}
\mathrm{CH}_{3}-\left(\mathrm{CH}_{2}\right)_{n}-\left(\mathrm{O}-\mathrm{CH}_{2}-\mathrm{CH}_{2}\right)_{n^{\prime}}-\mathrm{OH} \\
10 \leq \mathrm{n} \leq 18 \\
0 \leq \mathrm{n}^{\prime} \leq 20
\end{aligned}
$$

\section{(d) APEOs}

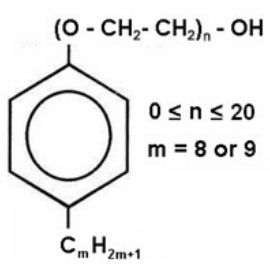

(e) QACs

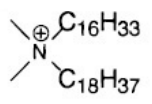<smiles>CCC[N+](C)(C)C</smiles>

Commercial DTDMAC

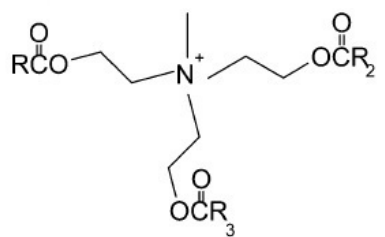

Esterquat

Figure 1. Chemical structures of (a) linear alkylbenzene sulfonates (LAS), (b) alkyl ethoxysulfates (AES), (c) alcohol polyethoxylates (AEOs), (d) alkylphenol polyethoxylates (APEOs), and (e) quaternary ammonium-based compounds (QACs).

personal care products [3-5]. Among the nonionic surfactants, alcohol polyethoxylates (AEOs) are currently produced in the greatest volume (e.g., 747000 tons in Europe in 2000), and alkylphenol ethoxylates (APEOs) are in second place by volume as a consequence of the restrictions on their use in recent years, due to the estrogenicity showed by some of their degradation intermediates [6-8]. AEOs are a mixture of homologues having from 12 to 18 carbon atoms in their alkyl chain, which is connected via an ether bond to an ethylene oxide (Figure 1c). APEOs are mixtures of a wide range of ethoxymers (from 1 to 20 EO units), and isomers, depending on the degree of branching of the alkyl chain (Figure 1d). Both, AEOs and APEOs, are widely employed in domestic and industrial applications [9] (e.g., detergents, emulsifiers, wetting and dispersing agents, industrial cleaners, textile, pulp and paper processing). Finally, quaternary ammonium-based compounds (QACs) are the main class of cationic surfactants, being constituted of at least one hydrophobic hydrocarbon chain linked to a positively charged nitrogen atom, and other alkyl groups which are mostly short-chain substituents such as methyl or benzyl groups (Figure 1e). Major uses of QACs are as fabric softeners and antiseptic agents in laundry detergents as well as other industrial uses [2]. Since the 1960's, the most commonly used active ingredient in fabric softeners has been dehydrogenated tallow dimethyl ammonium chloride (DTDMAC), with industry-wide European annual volumes exceeding 32000 tons through 1990. However, esterquat surfactants were introduced into the European market in the early 1990's because, due to their structure, they were more accessible to hydrolysis and biodegradation than DTDMAC. Hence, most fabric conditioners marketed now are comprised of esterquat types, with a volume of 130000 tons/year used in detergent products in the European Union [10-13]. 
Once used, the major fraction of synthetic surfactants are disposed down the drain to sewers, where it has been estimated that $50 \%$ by volume is degraded, $25 \%$ sorpted to suspended solids and $25 \%$ dissolved $[14,15]$. Later, these chemicals are commonly removed between 81 and $99.9 \%$ in wastewater treatment plants (WWTPs) [16-18], although they are frequently detected in sewage effluents showing concentrations up to $872 \mu \mathrm{g} / \mathrm{L}$ for LAS [16], between 0.24 and $3 \mu \mathrm{g} / \mathrm{L}$ for AES [19], up to $4 \mu \mathrm{g} / \mathrm{L}$ for QACs [20], and from 0.2 to $23 \mu \mathrm{g} / \mathrm{L}$ for AEOs and APEOs [21, 22]. Secondary treatment in active sludge units is considered the most important process to eliminate surfactants through aerobic biodegradation, but a considerable fraction is also removed by sorption / precipitation in sludges originated from several decantations (Figure 2) (e.g., 15-37\% of total LAS [14, 15, 23] and more than $90 \%$ of nonylphenol [24]). These sludges are also a potential source of contamination for soils, groundwater and adjacent rivers as they tend to contain high concentrations of organic contaminants and are often used in agriculture after anaerobic digestion. High levels of surfactants have been measured in treated sludges: up to $5400 \mathrm{mg} / \mathrm{kg}$ dry weight for LAS [15, 25], from 119.3 to $380.5 \mathrm{mg} / \mathrm{kg}$ for APEOs, AEOs and AES [25], and up to $5870 \mathrm{mg} / \mathrm{kg}$ for QACs [26, 27]. Any environmental compartment (surface waters, sediment, biota...) is susceptible of being contaminated by these compounds and/or their degradation metabolites [2, 28]. As example, a considerable number of studies have reported the presence of LAS in surface waters [29-31] at levels typically ranging from less than $1 \mathrm{ng} / \mathrm{L}$ to several hundreds of $\mu \mathrm{g} / \mathrm{L}$ respectively, depending on the distance from urban wastewater discharge sources and the type of wastewater treatment. Available studies about the presence, environmental behavior and distribution of non-ionic surfactants are mainly focused on NPEOs (nonylphenol polyethoxylates, which are the major fraction of APEOs). Concentrations of these compounds have been reported in surface waters all around the world: $<0.1$ to $100 \mu \mathrm{g} / \mathrm{L}$ in rivers in Mexico [32], Holland [33], Japan [34] and Taiwan [29], and from $<1$ to $38.5 \mu \mathrm{g} / \mathrm{L}$ in coastal waters of United States [35], Italy [30], Spain [36] and Israel [37]. Levels of surfactants in surface sediments are usually higher by several orders of magnitude than those measured in water due to their moderate to high sorption capacity. Thus, the presence of LAS [31, 38-40] and NPEOs [22, 41-44] has been widely detected in sediments, with levels ranging from less than 1 to more than $200 \mathrm{mg} / \mathrm{kg}$ and from less than 0.1 to $28.5 \mathrm{mg} / \mathrm{kg}$ respectively. Available data concerning to the presence of aliphatic anionic (AES) and nonionic (AEOs) surfactants, as well as cationic surfactants of any class, are rather limited. There are only a few papers about the occurrence of AEOs [36, 40,43,44] and AES $[19,31]$ in sediments, showing levels ranging from $<0.1$ to $23 \mathrm{mg} / \mathrm{kg}$. Some authors have also measured concentrations between $<0.1$ and $72 \mu \mathrm{g} / \mathrm{L}$ for AES $[19,31]$ and AEOs $[36,40,43]$ in surface waters. QACs have been measured at levels ranging from less than $2 \mu \mathrm{g} / \mathrm{L}$ in surface waters [20] to more than $100 \mathrm{mg} / \mathrm{kg}$ in sediments [45, 46].

Summarizing, huge volumes of surfactants are used every day, entering the environment, where these compounds and/or their degradation products may cause damage depending on their concentrations. Therefore, it becomes necessary developing reliable analytical methodologies that allow determining the levels of surfactants in environmental matrices, which may be complicated due several reasons. First, surfactants are often sold as commercial mixtures which can comprise hundreds of different homologues, isomers 


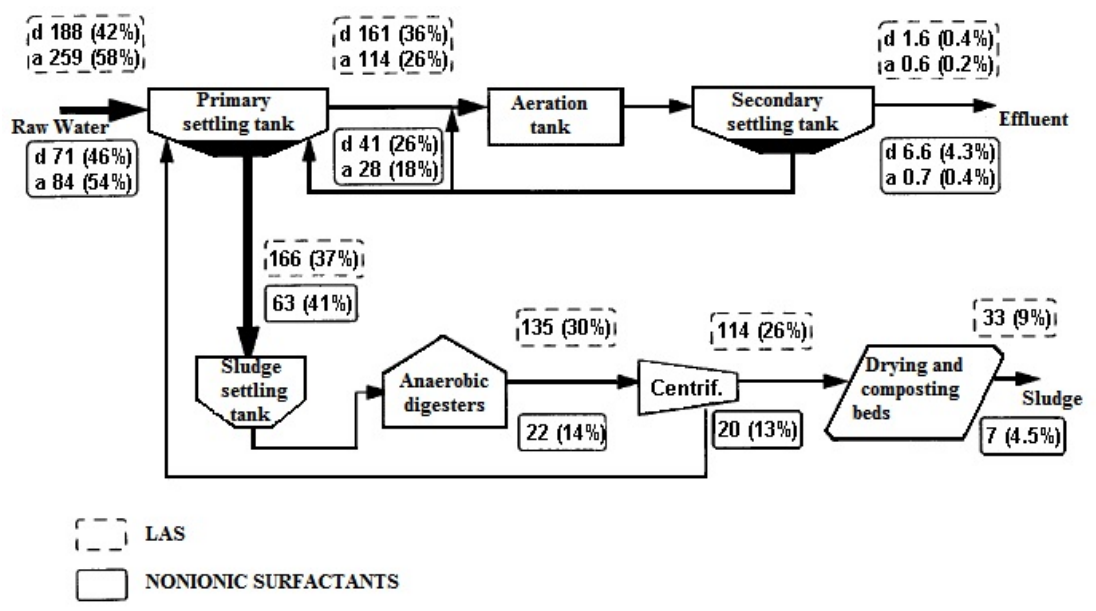

Figure 2. Flowsheet and sampling points of a wastewater treatment plant (WWTP). Figure shows mass balance of dissolved (d) and adsorbed/precipitated (a) of LAS and non-ionic surfactants. Absolute amount (average value in $\mathrm{kg} /$ day) and percentage with respect to raw water (adapted from reference [15]).

and/or ethoxymers with different physico-chemical properties. Separation and quantification of these components require the use of chromatographic techniques, mainly gas chromatography (GC) and liquid chromatography (LC). Achieving a successfully identification of every component in the mixture is also desirable for a better understanding of their environmental behavior as they may suffer differential degradation or sorption. There is also an additional challenge when dealing with target compounds that tend to be present at trace levels. In these cases it is necessary to develop reliable extraction, purification, and preconcentration protocols in order to remove as many interferences as possible before analysis without sacrificing high recovery values. Some of the techniques used to this end are also based on chromatographic techniques, such as solid phase extraction (SPE), directly derived from column chromatography. Thus, in this chapter we present the main problems posed by analysis of surfactants in environmental samples from two points of view:

- Isolation and/or preconcentration of surfactants from different types of samples;

- Separation, identification and quantification of analytes in properly prepared extracts.

\section{Sample pre-treatment}

Correct sampling of environmental samples is indispensable to provide representative information of the environmental compartments from which they are taken and, on the other hand, it is important to preserve the target compounds during storage [1]. Generally, water samples are often immediately preserved upon collection by the addition of biocides such as formaldehyde up to a concentration of $4 \%$ [17, 47], chloroform or sodium azide [20], 
or by filtering through a $0.45 \mu \mathrm{m}$ membrane filter [16]. Then, aliquots are kept at low temperatures and are often analyzed within a short period of time $(48 \mathrm{~h})$ in order to minimize the biodegradation of surfactants. Solid samples (sewage sludges, soils or sediments) are also kept at low temperature once they are collected to avoid any degradation of the analytes during the transport to the laboratory. Later, they are usually dried in a heater [47], at room temperature [25], or frozen at $-20{ }^{\circ} \mathrm{C}$ and later freeze-dried [48]. Once dried, samples are milled and strained through a sieve to a particle size of less than $2 \mathrm{~mm}$, and then stored at 4 to $-20^{\circ} \mathrm{C}$ for further extraction and analysis.

Surfactants are often found at trace levels (ppb or less) in environmental matrices, frequently below the limits of detection of most analytical techniques. Therefore, it is necessary to carry out not only their extraction but also their isolation and preconcentration to achieve proper identification and quantification. Those methodologies more commonly used at this preliminary stage are commented next for both solid and aqueous samples.

\subsection{Extraction from solid samples}

For several decades now, Soxhlet extraction and solid-liquid extraction (SLE) have been the most commonly used techniques for the extraction of surfactants and many other organic compounds from solid matrices. These methodologies are cheap and allow simple extraction, although they have also several disadvantages, including the large volume of solvent needed (from 150 to $500 \mathrm{~mL}[27,49,50]$ ), the long time required, which can take 418 hours per sample [20,51,52], and the production of toxic liquid wastes. Soxtec is an alternative extraction method based on Soxhlet, but the addition of several boiling and rinsing steps reduces the extraction time to $45 \mathrm{~min}$ and solvent consumption to $50-100 \mathrm{~mL}$ $[53,54]$. Application of ultrasounds followed by centrifugation or filtration to separate extracts from solid matrices is another cheap option for extracting surfactants due to the high extraction efficiency in a short time $[40,55,56]$. On the other hand, it also shows the same problems than SLE and Soxhlet extraction (high volume of organic solvents and toxic wastes). Table 1 summarizes the conditions used for the extraction of surfactants employing these conventional extraction techniques. As example, LAS and their degradation intermediates, sulfophenyl carboxylic acids (SPCs), have been extracted from sediments using methanol $(\mathrm{MeOH})$ as solvent $[50,52,57,58]$ by means of Soxhlet extraction and SLE. For APEOs and their metabolites, methodologies have been similar to those used for LAS [30,59,60], although methanol tends to be substituted by other less polar solvents (e.g., hexane [51] or dichloromethane (DCM) [61]), in order to enhance the extractability of the more hydrophobic compounds such as nonylphenol (NP). With respect to the extraction of aliphatic surfactants (AEOs and AES) and their main degradation products (polyethylenglycols, PEGs) from solid matrices, most authors have employed methanol $[19,40,62,63]$ and dichloromethane [55, 64] during Soxhlet or Soxtec extraction, SLE and sonication. There are still a few studies dealing with the application of all these techniques for extraction of QACs [26, 27, 65], but acidified methanol is used as solvent in most cases. 


\begin{tabular}{|c|c|c|c|c|c|c|}
\hline Analytes & Matrix & Method & Solvent & Other conditions & Clean-up & Ref. \\
\hline $\begin{array}{l}\text { LAS, AES, } \\
\text { AS }\end{array}$ & Sediment & $\begin{array}{l}\text { Soxhlet, } \\
\text { PLE }\end{array}$ & $\mathrm{MeOH}$ & $\begin{array}{l}\text { Time: } 5 \mathrm{~h}, \\
\text { Temperature: } 125^{\circ} \mathrm{C} \\
\text { Pressure: } 1500 \mathrm{psi}\end{array}$ & SPE (C18) & [62] \\
\hline NPEO, NP & Sediment & $\begin{array}{l}\text { Soxhlet, } \\
\text { Sonication }\end{array}$ & $\begin{array}{c}\text { Hexane/ } \\
\text { isopropanol, } \\
\text { Hexane/ acetone }\end{array}$ & $\begin{array}{l}\text { Time: } 18 \text { h, } \\
\text { Not spec. }\end{array}$ & SPE (cyanopropil) & [51] \\
\hline QAC & $\begin{array}{l}\text { Sediment, } \\
\text { sludge }\end{array}$ & Soxhlet & $\mathrm{MeOH} / \mathrm{HCl}$ & Time: $18 \mathrm{~h}$ & $\operatorname{LLE}\left(\mathrm{CHCl}_{3}\right.$, water $)$ & [20] \\
\hline $\begin{array}{c}\text { NPEO, } \\
\text { OPEO, AEO }\end{array}$ & Sludge & SLE & DCM & Time: $2 \mathrm{~h}$ & - & [64] \\
\hline $\begin{array}{l}\text { LAS } \\
\text { NPEO, }\end{array}$ & Soil & Soxtec & $\mathrm{MeOH}$ & Time: 45 min & - & [54] \\
\hline $\begin{array}{l}\text { OPEO, NP, } \\
\text { OP, AEO }\end{array}$ & Sludge & Soxtec & $\mathrm{MeOH}$ & Time: 45 min & SPE (C18) & [53] \\
\hline $\begin{array}{l}\text { LAS, SPC, } \\
\text { NPEO, } \\
\text { NPEC, AEO, } \\
\text { PEG }\end{array}$ & Sediment & Sonication & $\mathrm{MeOH}$ & Time: $30 \min \times 3$ & SPE (HLB) & [40] \\
\hline & & & & & $\operatorname{LLE}\left(\mathrm{CHCl}_{3}\right.$, water $)$ & \\
\hline QAC & Sediment & Sonication & $\mathrm{MeOH} / \mathrm{HCl}$ & Time: $1 \mathrm{~h} \times 3$ & $\begin{array}{c}+ \text { SPE (anion } \\
\text { exchange) }\end{array}$ & [65] \\
\hline $\begin{array}{l}\mathrm{NP}_{1-3} \mathrm{EO} \\
\mathrm{OP}_{1-3} \mathrm{EO}\end{array}$ & Sediment & Sonication & $\mathrm{MeOH}$ & Time: 7 min & $\begin{array}{c}\text { SPE (aminopropyl } \\
\text { silica) + LC } \\
\text { column (C18) } \\
\end{array}$ & [60] \\
\hline
\end{tabular}

Table 1. Overview of conventional extraction techniques applied to the extraction of surfactants and their metabolites from solid samples.

New extraction methods have been developed within the last decade not only to save time, but also to reduce solvent consumption without losing extraction efficiency. Table 2 shows some examples of the application of new techniques for the extraction of surfactants from solid environmental matrices. Microwave-assisted extraction (MAE) is suitable for the extraction of different anionic [66] and non-ionic [67] surfactants from sediments and sludges. Extractions are often achieved quickly at $120{ }^{\circ} \mathrm{C}$ using low solvent volumes (mainly $\mathrm{MeOH}$ [68] or DCM/MeOH [69]). Another advantage of MAE is that it can also be combined with Soxhlet extraction [70] in order to increase its efficiency. Less solvent demand and higher extraction rates compensate the high initial cost of acquiring a MAE unit. Pressurized fluid extraction (PFE), also known as accelerated solvent extraction (ASE) or pressurized liquid extraction (PLE), is a technique based on the use of high temperatures $\left(100-200{ }^{\circ} \mathrm{C}\right)$ and pressures (1500-3000 psi) to prevent solvents from boiling and to increase the kinetics of extraction. Therefore, PLE allows a faster extraction of organic compounds from solid samples (15-20 min per sample) with a lower uptake of organic solvent than more conventional techniques and without sacrificing high recovery values. Recently anionic [62, 71], cationic [72] and non-ionic [47, 73, 68] surfactants have been extracted using PLE and methanol or mixtures containing hexane, acetone, acetonitrile $(\mathrm{ACN})$ or even water as solvents. However, Petrovic et al. [74] observed the volatilization of some APEOs and their 
metabolites under these conditions, so they suggested keeping the extraction temperature under $60{ }^{\circ} \mathrm{C}$ in this case. Supercritical fluid extraction (SFE) is another extraction technique that has been recently applied to the extraction of ionic and non-ionic surfactants, using $\mathrm{CO}_{2}$ [75] or water [25] instead of toxic organic solvents to carry out the extraction in a short time and without requiring further clean-up steps [26]. Sometimes, the mobile phase $\left(\mathrm{CO}_{2}, \mathrm{H}_{2} \mathrm{O}\right)$ is modified with the addition of low molecular weight alcohols (e.g., $\mathrm{MeOH}$ ) to improve the efficiency in the extraction of polar or ionic compounds [76, 77]. However, better extraction recoveries for nonpolar compounds, possibility of using water as extraction solvent and automation of PLE has result in a lower interest of using SFE instead PLE for extraction of surfactants.

\begin{tabular}{|c|c|c|c|c|c|c|}
\hline Analytes & Matrix & Method & Solvent & Other conditions & Clean-up & Ref. \\
\hline $\begin{array}{c}\text { LAS, SPC, } \\
\text { AES, AS, } \\
\text { NPEO, APEC, } \\
\text { AEO }\end{array}$ & Sediment & PLE & $\mathrm{MeOH}$ & $\begin{array}{l}\text { Time: } 15 \mathrm{~min} \\
\text { Temperature: } 120^{\circ} \mathrm{C} \\
\text { Pressure: } 1500 \mathrm{psi}\end{array}$ & SPE (C18) & [47] \\
\hline LAS, SPC & Soil & PLE & $\mathrm{MeOH} / \mathrm{H}_{2} \mathrm{O}$ & $\begin{array}{l}\text { Time: } 15 \mathrm{~min} \\
\text { Temperature: } 120^{\circ} \mathrm{C} \\
\text { Pressure: } 1500 \mathrm{psi}\end{array}$ & SPE (C18) & [71] \\
\hline $\begin{array}{l}\mathrm{NP}_{1-5 \mathrm{EO}}, \mathrm{OP} 1- \\
{ }_{5} \mathrm{EO}, \mathrm{NP}, \mathrm{OP}\end{array}$ & Sediment & PLE & Acetone/hexane & $\begin{array}{l}\text { Time: } 15 \mathrm{~min} \\
\text { Temperature: } 100{ }^{\circ} \mathrm{C} \\
\text { Pressure: } 1500 \mathrm{psi}\end{array}$ & $\begin{array}{l}\text { SPE (aminopropyl } \\
\text { silica) }\end{array}$ & [73] \\
\hline QAC & Sediment & PLE & $\mathrm{ACN} / \mathrm{H}_{2} \mathrm{O}$ & $\begin{array}{l}\text { Temperature: } 120^{\circ} \mathrm{C} \\
\text { Pressure: } 1500 \mathrm{psi}\end{array}$ & SPE (polymeric) & [72] \\
\hline NPEO, NP & Sediment & $\begin{array}{l}\text { Soxhlet, } \\
\text { PLE, MAE }\end{array}$ & $\mathrm{MeOH}$ & $\begin{array}{c}\text { Time: } 10 \mathrm{~h}, \\
\text { Time: } 10 \mathrm{~min} \\
\text { Temperature: } 100{ }^{\circ} \mathrm{C} \\
\text { Pressure: } 1500 \mathrm{psi} \text {, } \\
\text { Time: } 20 \mathrm{~min}\end{array}$ & $\begin{array}{l}\text { LC column } \\
\text { (alumina) }\end{array}$ & [68] \\
\hline LAS & Sludge & SFE & $\mathrm{CO}_{2}$ & Time: 15 min & Not required & [75] \\
\hline QAC & Sludge & SFE & $\mathrm{CO}_{2} / \mathrm{MeOH}$ & Time: $45 \mathrm{~min}$ & $\begin{array}{l}\mathrm{LLE}\left(\mathrm{CHCl}_{3} \text {, water }\right) \\
+\mathrm{LC} \text { column (anion } \\
\text { exchange) }\end{array}$ & [77] \\
\hline $\begin{array}{c}\text { LAS, AS, AES, } \\
\text { AEO, NPEO, } \\
\text { NPEC, AP }\end{array}$ & Sludge & SFE & Water & Time: $27 \mathrm{~min}$ & SPE (carbograph 4) & [25] \\
\hline NP, OP & Sediment & MAE & DCM/MeOH & Time: 25 min & $\begin{array}{l}\text { SPE (polyestyrene- } \\
\text { divinylbenzene) }\end{array}$ & [69] \\
\hline LAS & Sludge & MAE & $\mathrm{MeOH}$ & Time: $10 \mathrm{~min}$ & Not required & [66] \\
\hline
\end{tabular}

Table 2. Overview of modern extraction techniques applied to the extraction of surfactants and their metabolites from solid samples.

\subsection{Purification and preconcentration}

There is a wide variety of techniques to carry out purification and preconcentration of extracts from solid samples, as well as aqueous samples, before proceeding with analysis of 
surfactants and their degradation metabolites. Liquid-liquid extraction (LLE) is among the first techniques that have been widely applied for the extraction of ionic and non-ionic surfactants. Target compounds are isolated from the sample according to their relative solubilities in two different immiscible o partially miscible liquid phases, usually water and an organic solvent. Several cationic [20, 65] and anionic compounds [78, 79] have been extracted from aqueous samples using chloroform, whereas dichloromethane [80] and ethyl acetate [81] have been used to isolate non-ionic surfactants from water. The main advantage of LLE is that it can be used to determine total concentration of these compounds in water in spite of their solid particle matter level. However, the tendency of surfactants to concentrate at phase boundaries leads to the formation of emulsions, and phase separation during LLE becomes very difficult. This can be avoided by the formation of liphopilic ion pairs between surfactants and ion-pair reagents [1] (e.g., disulphine blue dyes or LAS for cationic surfactants [65, 77, 82], methylene blue [78, 79, 83] or methylene green for anionic surfactants [84], modified Dragendorff reagent for non-ionic [81]).

Nowadays, solid-phase extraction (SPE) is the most extended purification and preconcentration technique for surfactants. LLE requires large amounts of sample (100-500 $\mathrm{mL}$ ) and high consumption of toxic organic solvents, while SPE is generally faster and needs lower sample and solvent volumes $(7-100 \mathrm{~mL}$ and 5-20 mL, respectively). Briefly, SPE consists on passing the aqueous sample or extract (mobile phase) through a specific material (solid phase) that retains analytes whereas water, salts and other interferences are discarded. Later, target compounds can be eluted from the solid phase using a minimal amount of solvent (few milliliters) so a clean and low volume extract is obtained. Table 3 shows general information about protocols developed for the isolation of surfactants using both SPE and LLE. SPE has been widely applied to isolate anionic surfactants from aqueous samples. More specifically, octadecylsilica (C18) has been used as the main solid phase to extract LAS and their degradation products (SPCs) from water samples [62, 71], while methanol is commonly employed as elution solvent. Due to the negative charge of these analytes, strong anionic-exchange (SAX) resins have been also employed, alone or combined with C18, for a better purification $[52,85]$, using a mixture of methanol and hydrochloric acid as elution solvent $[57,58]$. Lowering the $\mathrm{pH}$ of the sample and/or adding significant amounts of salts such as sodium chloride [52, 71] (salting-out effect) is also convenient to improve the retention of most polar components (e.g., SPCs). Other authors have preferred using graphitized black carbon (GBC) [29, 86] or polystyrene-divinylbezene SDB-1 cartridges [87] instead, also showing good extraction recoveries. Other anionic surfactants (AES and AS) have been successfully isolated by octadecylsilica $[62,85]$ and GBC $[25,88]$ SPE cartridges from river, marine and wastewater samples, as well as sludge and sediment extracts. Regarding non-ionic surfactants, a wide variety of different protocols has been developed to extract AEOs and APEOs and their degradation products from liquid samples. Thus, GBC $[89,90]$ and silica (C2 to C18) cartridges [53, 91, 92], along with methanol, dichloromethane, ethyl acetate and/or acetonitrile as elution solvents, have been employed, sometimes combined with strong cationic-exchange (SCX) and SAX cartridges [90, 92] for the removal of potential anionic and cationic interferences as non-ionic compounds are not retained due 
to their neutral charge. Additionally, octadecylsilica has been applied to extract the most hydrophobic group of NPEOs metabolites, constituted by NP and short chain oligomers (NP1-3EOs), using mainly methanol, acetone or dichloromethane as elution solvents [60, 73]. SAX disks have been also used instead of conventional SPE cartridges to isolate nonylphenol polyethoxycarboxylates (NPECs), NPEO polar degradation products, from sludge extracts. Cassani and co-workers [93] also employed disks (C18) for determination of AEOs in sludge samples and wastewaters. Overall, most authors employ C18 [47, 55] and GBC cartridges $[25,88]$ because they are suitable for simultaneous isolation of a wide range of anionic (LAS and AES) and non-ionic (AEOs and NPEOs) surfactants, as well as their polar metabolites (PEGs, NPECs and SPCs), in a single stage by fractional elution using mixtures of hexane, dichloromethane, methanol, acetone and ethyl acetate. New polymeric materials are also currently being tested for the extraction of these compounds [51, 73, 69]. Thus, the hydrophilic-lipophilic copolymer Oasis HLB has been presented by Lara-Martín and co-workers [40] as an alternative for the simultaneous isolation of LAS, NPEOs, their carboxylated metabolites (SPCs and NPECs), and AEOs and their polar degradation intermediates (PEGs) from liquid samples in one single purification step. On the other hand, research on the isolation of cationic surfactants using SPE from water samples [94-97] and sediment extracts [72] is more limited. Nonpolar silica sorbents (e.g., C18) are not suitable for QACs because the strong interaction of these compounds with the silanol groups results in very broad elution bands [98]. This issue has been partially solved employing neutral polymeric sorbents instead [72, 96], although better results are obtained using sodium dodecyl sulphate (SDS) hemimicelles attached to alumina or anion exchange resins [94, 95, 97]. Despite this, LLE is still considered to be more effective than SPE for extraction of cationic surfactants from liquid samples [27].

In the past few years, advances in SPE have led to new related techniques such as matrix solid-phase dispersion (MSPD), which is used to extract and purify target compounds simultaneously from solid matrices. In the case of surfactants, this extraction protocol has been mainly applied to fish samples [99], where aliquots are taken and mixed with octadecyl silica in a column, in order to isolate LAS and SPCs, as well as non-ionic surfactants. Afterwards, strong non-polar solvents (e.g., hexane) and methanol are used to remove fats in a first clean-up stage and to extract surfactants after another elution, respectively. There are other simple and low cost extraction techniques which reduce the time needed for sample preparation, and decrease or eliminate solvent consumption [100-111]. As example, dispersive liquid-liquid microextraction (DLLME) is a novel method based on the migration of analytes to a cloudy solution, caused by the dispersion of the extraction solvent (low soluble in water, e.g., chloroform) as very fine droplets due to the appropriate mixture with a dispersant (soluble in water, e.g., acetone) in the aqueous sample. Then, these dispersed fine particles of the extraction phase containing analytes are sedimented in the bottom of a test tube by centrifugation [100]. The main difficulties associated with DLLME are the vulnerability of solvent drop to physic forces and automation issues. This problem of physical instability could be solved by the application of hollow fiber membranes which are impregnated by an organic solvent (e.g., 1-octanol) and placed into the water sample for 


\begin{tabular}{|c|c|c|c|c|c|}
\hline Analytes & $\begin{array}{l}\text { Sample } \\
\text { volume }\end{array}$ & Method & $\begin{array}{l}\text { Solid } \\
\text { phase }\end{array}$ & Isolation conditions & Ref. \\
\hline QAC & $100 \mathrm{~mL}$ & LLE & - & $\begin{array}{l}\text { Solvent: chloroform }(15 \mathrm{~mL}) \\
\text { Washing: water } \\
\text { Ion-par reagent: Patent Blue V }\end{array}$ & [82] \\
\hline LAS, SPC & $500-1000 \mathrm{~mL}$ & LLE & - & $\begin{array}{l}\text { Solvent: chloroform }(3 \times 4 \mathrm{~mL}) \\
\text { Ion-par reagent: methylene green }\end{array}$ & [84] \\
\hline$N_{1-2} E O, N P, O P$ & $300 \mathrm{~mL}$ & LLE & - & Solvent: DCM (300 mL) & [80] \\
\hline QAC & $20 \mathrm{~mL}$ & LLE & - & $\begin{array}{l}\text { Solvent: chloroform }(5 \mathrm{~mL}) \\
\text { Ion-par reagent: disulphine blue }\end{array}$ & [79] \\
\hline LAS, AES, AS & $10-200 \mathrm{~mL}$ & SPE & $\begin{array}{c}\text { C18+SAX } \\
\text { (LAS) } \\
\text { C2 (AES, } \\
\text { AS) }\end{array}$ & $\begin{array}{l}\text { 1. Conditioning: } \mathrm{MeOH} \text {, water } \\
\text { 2. Washing: } \mathrm{MeOH} / \text { water } \\
\text { 3. Elution: } \mathrm{MeOH}+\mathrm{HCl} / \mathrm{MeOH} \\
\text { 1. Conditioning: } \\
\mathrm{MeOH} \text { /isopropanol, water } \\
\text { 2. Washing: water } \\
\text { 3. Elution: } \mathrm{MeOH} / \text { isopropanol }\end{array}$ & [85] \\
\hline AEOs & $50-2000 \mathrm{~mL}$ & SPE & $\begin{array}{l}\mathrm{C} 2+\mathrm{SCX}+ \\
\mathrm{SAX}\end{array}$ & $\begin{array}{l}\text { 1. Conditioning: Not spec. } \\
\text { 2. Fractionation: } \mathrm{ACN} \\
\text { 3. Fractionation: } \mathrm{MeOH} / \mathrm{ethyl} \\
\text { acetate/water }\end{array}$ & [92] \\
\hline QAC & $50 \mathrm{~mL}$ & SPE & Alumina & $\begin{array}{l}\text { 1. Passing solution with SDS } \\
\text { 2. Elution: } \mathrm{MeOH}\end{array}$ & [95] \\
\hline NPEO, NPEC & $100 \mathrm{~mL}$ & SPE & GBC & $\begin{array}{l}\text { 1. Conditioning: } \mathrm{DCM}, \mathrm{DCM} / \text { formic } \\
\text { acid, } \mathrm{MeOH} \text {, acidified water } \\
\text { 2. Washing: } \mathrm{MeOH} / \text { water, } \mathrm{MeOH} \\
\text { 3. Elution: } \mathrm{DCM} / \text { formic acid }\end{array}$ & [89] \\
\hline LAS, SPC & $25-250 \mathrm{~mL}$ & SPE & C18+SAX & $\begin{array}{l}\text { 1. Conditioning: } \mathrm{MeOH} \text {, water } \\
\text { 2. Washing: water, acidified water } \\
\text { 3. Elution: } \mathrm{MeOH}+\text { acidified } \mathrm{MeOH}\end{array}$ & [52] \\
\hline QAC & $100 \mathrm{~mL}$ & SPE & Strata-X & $\begin{array}{l}\text { 1. Conditioning: } \mathrm{ACN} \text {, water } \\
\text { 2. Washing: water } \\
\text { 3. Elution: } \mathrm{ACN} / \text { acetic acid/water }\end{array}$ & [96] \\
\hline $\begin{array}{l}\text { LAS, NPEO, } \\
\text { NPEC, AEO, } \\
\text { PEG, NP, OP }\end{array}$ & $200 \mathrm{~mL}$ & SPE & $\mathrm{C} 18$ & $\begin{array}{l}\text { 1. Conditioning: } \mathrm{MeOH} \text {, water } \\
\text { 2. Fractionation: hexane/DCM } \\
\text { 3. Fractionation: } \mathrm{MeOH} / \mathrm{DCM}\end{array}$ & [55] \\
\hline
\end{tabular}

Table 3. Overview of LLE and SPE techniques used for clean-up and preconcentration of surfactants from environmental samples.

equilibrium extraction of the target compounds. Finally, the fiber is removed from the sample and extracted analytes are desorbed by diffusion into a different solvent (e.g., $\mathrm{MeOH}$ ) [101]. This technique has been recently applied to isolation of cationic [101, 102], non-ionic [103] and anionic surfactants [104] from aqueous samples. Solid-phase microextraction (SPME) and stir-bar sorptive extraction (SBSE) can be also considered for rapid isolation of surfactants. Both techniques are based on the diffusion of analytes from the sample directly, without requiring any organic solvent, into a fiber or bar made of a specific polymer. The amount of polymer changes from $0.5 \mu \mathrm{L}$ in SPME fibers up to $300 \mu \mathrm{L}$ 
in SBSE bars, therefore improving the sensitivity of target compounds. Different types of fibers have been tested during application of SPME for isolation of anionic (polydimethylsiloxane (PDMS) [105], polyacrylate (PA) [106]) and non-ionic surfactants (carbowax/template resin (CWAX/TR) [107], PDMS/divinylbenzene (DVB), PA [108]). So far, the use of SBSE is limited to the extraction of NP and octylphenol (OP) from liquid samples [109]. Once they are captured by the polymer in the fiber or the bar, analytes are released by heat in the injection port of GC systems (thermal desorption), or by reduced amount of solvents before injection on LC systems (liquid desorption).

\section{Separation, identification and quantification of synthetic surfactants}

Over the last decades, analysis of surfactants in environmental samples has been carried out using several instrumental techniques. So far, spectrophotometric, potentiometric titrametration (PT) and tensammetric tecniques have been optimized to measure the total content of ionic [112-114] and non-ionic surfactants [115, 116], although their sensitivity and/or specifity tend to be low compared to chromatographic techniques coupled to several types of detectors. Generally, one of the main applications of spectrophotometric techniques has been routine environmental analysis due to their quickness and simplicity. They involve the formation of ion associates of analytes with specific ion-pair reagents and their extraction into appropriated organic solvents. After phase separation, the absorbance of the organic phase is measured. However, despite the advantages described above, the use of spectrophotometry generates very toxic wastes (e.g., chloroform) and is only limited to the analysis of total amount of surfactants [117-119]. PT and tensammetric techniques [120, 121] are based on the changes in electric properties caused by the presence of analytes in environmental samples. They can be only applied to the determination of total ionic and nonionic compounds, being impossible for both techniques to discriminate among individual components from surfactant mixtures. Besides, there are also issues associated with reproducibility and signal stability [113]. Nowadays, it is necessary to go beyond quantification of the total concentration of target analytes and, in most cases, chromatographic techniques (gas chromatography, GC, or high-performance liquid chromatography, HPLC) coupled to various types of detectors are preferred to separate and identify each individual compound from surfactant mixtures.

\subsection{Gas chromatography}

Less frequently used than HPLC for analysis of surfactants, the main drawback of GC is that all anionic and non-ionic compounds and their metabolites need to be derivatized with specific agents to solve sensitivity, separation or volatilization issues before injecting them into the system. Most commonly used derivatizing agents are trifluoroethanol [29, 58], diazomethane [84], N,O-bis(trimethylsilyl)trifluoro acetamide (BSTFA) [53, 59, 122], acetic anhydride [61, 109] and hydrogen bromide [90], among other reactants. In any case, some low molecular mass metabolites of non-ionic surfactants (NP and short-chain NPEOs) have been analyzed directly by GC $[67,80]$ as they are volatile enough, although better results can be 
obtained if derivatization is performed. There are also some advantages in using GC over HPLC. Thus, GC columns have a better capability for achieving complete separation of homologues and isomers of many surfactants after derivatization. This may be a key aspect for those studies on the biodegradability or toxicity of surfactants such as LAS or NPEO, which can change depending on the length of the alkyl chain and/or the position of the phenyl ring [123] (Figures 3a and b). In most cases, anionic and non-ionic surfactants have been separated by nonpolar capillary columns containing 5\%-phenyl-95\%-dimethylpolysiloxane (e.g., HP-5 $[58,75,67]$, SE-54 [76], DB-5 [84, 103, 109]), and a mobile phase comprised of high purity helium as carrier gas with a flow rate from 0.58 to $3.4 \mathrm{~mL} / \mathrm{min}$. Regarding cationic surfactants, the application of GC to their separation and analysis has not been mentioned in any paper so far [1]. Table 4 describes general information about some analytical protocols for determination of anionic and nonionic surfactants by means of GC in environmental samples.

Several types of detectors can be used after gas chromatography for the analysis of target compounds, such as flame-ionization detectors (FID), which were used for the analysis of

(a)
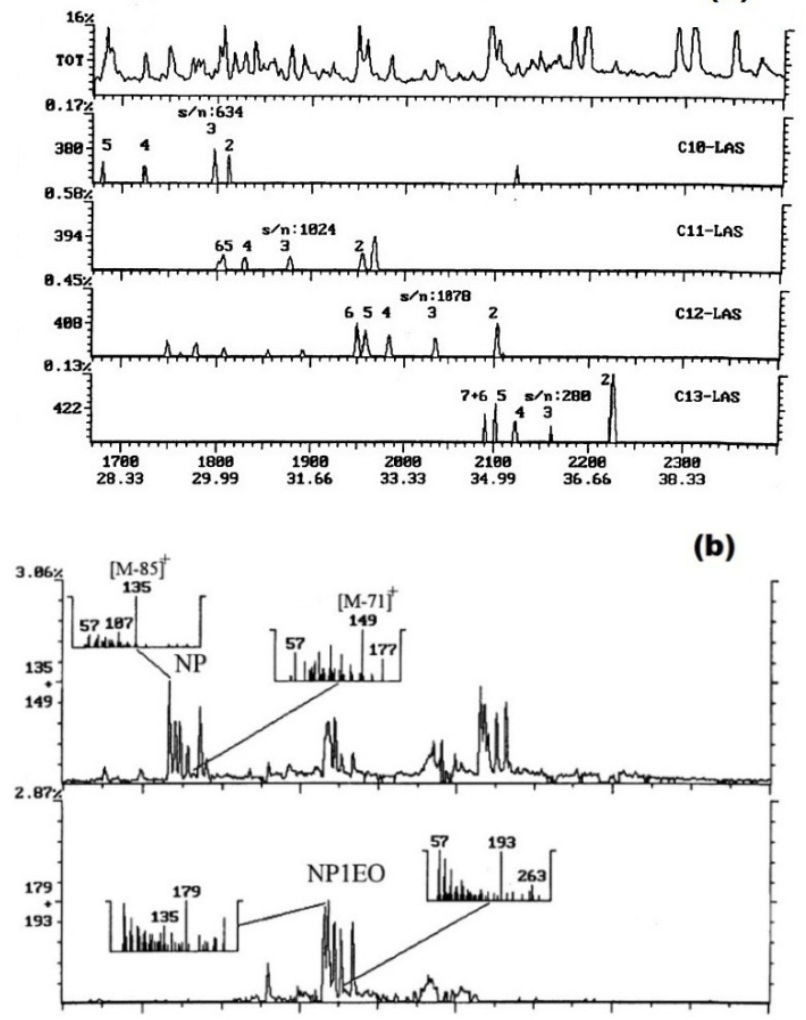

Figure 3. Selected GC-EI-MS characteristic ion chromatograms from a river sample, showing resolution of the derivatives of (a) LAS [145], and (b) NP and NP1EO (with their corresponding mass spectra) [144]. 
anionic surfactants in water samples [124]. Nowadays, single quadrupole (MS) or tandem mass spectrometers (MS-MS) are commonly preferred because they allow unequivocal identification of analytes by measuring their parent masses and displaying specific fragmentation patterns after their ionization and rupture, respectively. Hence, there are several papers dealing with the analysis of anionic and non-ionic surfactants using GC coupled to MS [69, 105, 108] or MS-MS [125]. Target compounds can be detected by electron impact (EI) or chemical ionization (CI), being more widely used the first mode, although higher sensitivity may be reached using CI for analysis of some anionic compounds.

\begin{tabular}{|c|c|c|c|c|c|c|c|c|}
\hline $\begin{array}{c}\text { Target } \\
\text { compounds }\end{array}$ & Matrix & $\begin{array}{c}\text { Sample } \\
\text { preparation }\end{array}$ & $\begin{array}{c}\text { Recovery } \\
(\%)\end{array}$ & $\begin{array}{l}\text { Mobile } \\
\text { phase }\end{array}$ & Column & Detection & $\begin{array}{l}\text { LOD/ } \\
\text { MLD }\end{array}$ & Ref \\
\hline LAS & $\begin{array}{c}\text { Wastewa } \\
\text { ter, } \\
\text { seawater }\end{array}$ & $\begin{array}{l}\text { Ion pair SPME } \\
\text { Derivatization in } \\
\text { GC injection } \\
\text { port (tetrabutyl } \\
\text { ammonium) }\end{array}$ & - & - & $\begin{array}{c}\text { BPX5 } \\
\text { (capillary } \\
\text { column, } 30 \\
\mathrm{~m}, 0.25 \mathrm{~mm} \\
\text { ID, } 0.25 \mu \mathrm{m} \text { ) }\end{array}$ & $\mathrm{EI}(+)-\mathrm{MS}$ & $\begin{array}{l}0.16- \\
0.8 \mathrm{ng} / \\
\mathrm{mL}\end{array}$ & [105] \\
\hline $\begin{array}{c}\text { NP1-3EO, NP } \\
\text { NP1-3EC } \\
\text { LAS, SPC }\end{array}$ & $\begin{array}{c}\text { River } \\
\text { water, } \\
\text { wastewa } \\
\text { ter }\end{array}$ & $\begin{array}{c}\text { SPE (without } \\
\text { derivatization) } \\
\text { Derivatization } \\
\left(\mathrm{C}_{3} \mathrm{H}_{7} \mathrm{OH} /\right. \\
\left.\mathrm{CH}_{3} \mathrm{COCl}\right) \\
\text { Derivatization } \\
\left(\mathrm{SOCl}_{2} /\right. \\
\left.\mathrm{CF}_{3} \mathrm{CH}_{2} \mathrm{OH}\right)\end{array}$ & $\begin{array}{c}81-90 \text { (NP) } \\
\\
75-112 \\
\text { (LAS, SPC) }\end{array}$ & - & $\begin{array}{c}\text { DB-5 } \\
\text { (capillary } \\
\text { column, } 30 \\
\mathrm{~m}, 0.25 \mathrm{~mm} \\
\text { ID, } 0.25 \mu \mathrm{m} \text { ) }\end{array}$ & $\begin{array}{c}\mathrm{EI} / \mathrm{CI}(+)- \\
\mathrm{MS}\end{array}$ & $\begin{array}{c}\leq 0.01 \\
\mu g / L \\
(L O Q)\end{array}$ & $\begin{array}{l}{[29,} \\
143, \\
144]\end{array}$ \\
\hline $\begin{array}{c}\text { AEOs } \\
\left(\mathrm{C}_{12}-\mathrm{C}_{15}\right)\end{array}$ & $\begin{array}{c}\text { Wastewa } \\
\text { ter, river } \\
\text { water }\end{array}$ & $\begin{array}{c}\text { SPE } \\
\text { Derivatization } \\
(\mathrm{HBr})\end{array}$ & $65-102$ & Helium & $\begin{array}{c}\text { Rtx-1 } \\
\text { (capillary } \\
\text { column, } 60 \\
\mathrm{~m}, 0.25 \mathrm{~mm} \\
\mathrm{ID}, 0.25 \mu \mathrm{m} \text { ) }\end{array}$ & EI(-)-MS & $\begin{array}{c}0.001- \\
0.01 \\
\mathrm{mg} / \mathrm{L}\end{array}$ & [90] \\
\hline $\mathrm{NP}_{1-2 \mathrm{EO}}, \mathrm{NP}$ & $\begin{array}{c}\text { Marine } \\
\text { sediment }\end{array}$ & $\begin{array}{c}\text { MAE, SPE } \\
\text { (without } \\
\text { derivatization) }\end{array}$ & 100 & $\begin{array}{l}\text { Helium } \\
\qquad(2 \\
\mathrm{mL} / \mathrm{min})\end{array}$ & $\begin{array}{c}\text { HP-5 } \\
\text { (capillary } \\
\text { column, } 30 \\
\mathrm{~m}, 0.25 \mathrm{~mm} \\
\mathrm{ID}, 0.25 \mu \mathrm{m} \text { ) }\end{array}$ & $\mathrm{EI}(+)-\mathrm{MS}$ & $100 \mathrm{ng}$ & [67] \\
\hline $\mathrm{NP}, \mathrm{OP}$ & $\begin{array}{l}\text { River } \\
\text { water }\end{array}$ & $\begin{array}{c}\text { DLLME } \\
\text { Derivatization } \\
\text { in situ (methyl } \\
\text { chloroformate) }\end{array}$ & $88.3-106.7$ & $\begin{array}{l}\text { Helium } \\
\qquad(1 \\
\mathrm{mL} / \mathrm{min})\end{array}$ & $\begin{array}{l}\text { DB-5 (fused } \\
\text { silica } \\
\text { capillary } \\
\text { column, } 30 \\
\mathrm{~m}, 0.25 \mathrm{~mm} \\
\mathrm{ID}, 0.25 \mu \mathrm{m} \text { ) }\end{array}$ & $\mathrm{EI}(+)-\mathrm{MS}$ & $\begin{array}{c}0.002- \\
0.03 \\
\mu \mathrm{g} / \mathrm{L}\end{array}$ & [103] \\
\hline $\mathrm{NP}, \mathrm{OP}$ & $\begin{array}{c}\text { River } \\
\text { water, } \\
\text { sediment }\end{array}$ & $\begin{array}{l}\text { MAE, SPE } \\
\text { Derivatization } \\
\text { (BSTFA) }\end{array}$ & 77-109 & $\begin{array}{l}\text { Helium } \\
\qquad(1 \\
\mathrm{mL} / \mathrm{min})\end{array}$ & $\begin{array}{c}\text { HP-5 } \\
\text { (capillary } \\
\text { column, } 30 \\
\mathrm{~m}, 0.25 \mathrm{~mm} \\
\mathrm{ID}, 0.25 \mu \mathrm{m} \text { ) }\end{array}$ & $\begin{array}{l}\text { EI(+)- } \\
\text { MS-MS }\end{array}$ & $\begin{array}{c}0.01- \\
0.1 \\
\mathrm{ng} / \mathrm{L} \\
0.08- \\
0.14 \\
\mathrm{ng} / \mathrm{g}\end{array}$ & [125] \\
\hline
\end{tabular}

Table 4. Key aspects of GC analysis of surfactants in different environmental matrices. 


\subsection{Liquid chromatography}

High-performance liquid chromatography (HPLC) is currently the most commonly used technique for separation and analysis of commercial mixtures of surfactants in the environment, mainly due to its advantages over GC because HPLC is suitable for determining non volatile analytes from low to high molecular weight and derivatization is unnecessary in most cases. Reverse-phase columns, mainly RP-18 [47, 96, 106] and RP-8 [52, 95], are often employed for chromatographic separations of anionic, non-ionic, cationic surfactants and their degradation products. Mobile phases are solvent mixtures containing deionized water, acetonitrile and/or methanol. Separation can be improved by adding some additives (e.g., ammonium acetate (AMAC), triethylamine) to the mobile phase, as well as acetic (AA) or formic acid (FA) as modifiers [72, 71, 89]. There are also a few works showing efficient separation of NPEOs ethoxymers, some of their metabolites [126] and QACs [101] by amino-silica or cyanopropyl normal phase columns, although the elution order is reversed (more hydrophobic compounds, such as NP, elute first and NPEOs last). In these cases, stronger non-polar solvents (e.g., hexane, chloroform and isopropanol) are preferred. Additionally, some researchers have used new stationary phases that are specific for the separation of ethoxylated surfactants. As example, Lee Ferguson and co-workers [60, 127] tested a mixed-mode HPLC system using a column packed with a polymeric phase capable of separating NPEO and NP components by both size-exclusion and reversed-phase adsorption mechanisms (Figure 4a). Other authors have also applied this technique with some modifications to quantify OP and octylphenol ethoxylates (OPEOs) in environmental samples [73]. Alternative packing materials containing hydrophobic (alkyl chains) and hydrophilic (amide) functional groups to improve the simultaneous separation of cationic, anionic and non-ionic surfactants have also been occasionally employed [128].

Some surfactant classes (e.g., LAS and NPEOs) and their metabolites are still good candidates, due to the presence of an aromatic ring in their molecular structure, to be analyzed by the first quantitative methods based on the use of HPLC coupled to ultraviolet (UV) or fluorescence detectors (FL) [68, 66, 126, 129, 130]. The presence of a benzene group also facilitates the use of UV for identifying some specific cationic surfactants such as benzalkonium chlorides (BACs) [97]. Moreover, HPLC coupled to FL detector was employed by Natkae and co-workers [131] to achieve partial separation of positional isomers and obtain information on the alkyl chain distributions of LAS in river water samples. However, aliphatic surfactants (e.g., AEOs and AES) have not been monitored so much due to their lack of UV absorbance or fluorescence. Prior derivatization using phenylisocyanate [132], naphthyl isocyanate and naphthyl chloride (NC) [88, 133], among others, must be carried out. Nowadays, however, this kind of surfactants, along with LAS, NPEOs and many other organic microcontaminants, are preferably determined by HPLC-MS, which offers several advantages over other detectors such as sensitivity, selectivity, and simultaneous identification and confirmation of multiple analyte classes by means of their molecular weight, retention time and mass spectra. In this sense, considerable progress has been achieved in the environmental analysis of surfactants over the last decade due to the development of atmospheric pressure ionization (APCI) or electrospray ionization (ESI) 
interfaces that allow coupling HPLC to MS. Before this, mass spectrometry was used only for identification of a wide range of surfactants from their mass spectra by flow-injection analysis (FIA) [134].
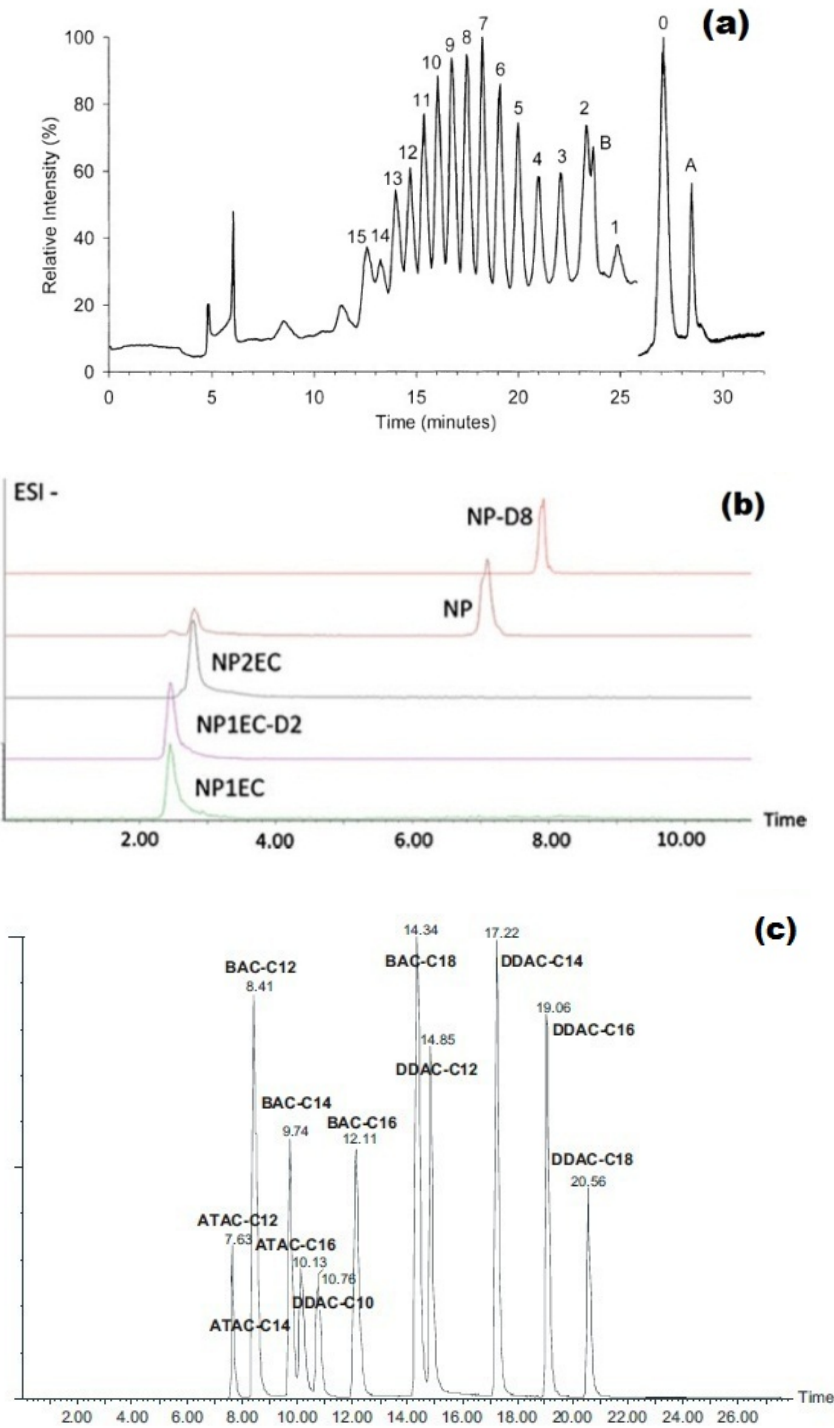

Figure 4. (a) Mixed-mode HPLC-ESI-MS total current ion chromatogram of NPEOs $(A=N P, B=n-$ $\mathrm{NP}_{3} \mathrm{EO}, 0=\mathrm{NP}, 1=\mathrm{NP} \mathrm{EO}_{1}$, etc.) from a sediment sample, switching MS polarity from positive to negative ion mode at retention time $25.8 \mathrm{~min}$ [60]; (b) UPLC-ESI-MS-MS extracted ion chromatograms showing the occurrence of NPEO metabolites in a sediment sample [44]; and (c) HPLC-MS-MS chromatogram of a standard solution of QACs [141]. 
Among different types of mass analyzers used for the identification and quantification of surfactants, there are several authors that have employed single quadrupole HPLC-MS systems operating in selected ion monitoring (SIM) mode [25, 55]. However, isobaric interferences may lead to sensitivity and resolution issues, which have been commonly solved by means of triple quadrupole [27, 106, 135] or ion trap MS detectors [47, 94]. In recent years, both techniques, especially the first one, have been the main tool for trace analysis of surfactants and many other organic contaminants because their respective MSMS (triple quadrupole) and MS (ion trap) capabilities allow scanning for daughter ions, increasing sensitivity and selectivity (especially for analysis of environmental samples which contain compounds showing the same molecular ions and retention times than those for selected analytes) [72] (Figures $4 \mathrm{~b}$ and c). As example, discrimination and quantification of the 20 positional isomers of LAS was achieved recently by Lunar and co-workers [136] by monitoring specific fragment ions resulting from the benzylic cleavage of the carbon alkyl chain on both sides of the LAS phenyl group. As a drawback of this type of MS detectors, there is a limited number of predetermined ions that can be monitored during a single experiment and, although less frequent than in single quadrupole MS, interferences may lead to overestimation in the concentration of target compounds. Time-of-flight (ToF) LCMS systems are less commonly used than other MS analyzers for environmental analysis of surfactants, but their full scan spectral sensitivity in a wide mass range and accurate mass measurement allow the identification and quantification of a large number of target, nontarget surfactants and their metabolites in all kinds of matrices [40,65, 137], constituting a recent alternative to address the issues mentioned above. Occasionally, hybrid systems like quadrupole time-of-flight (Q-ToF) detectors have been applied to determine a wide range of surfactants and some of their degradation products, such as alkylphenols and their carboxylates, in textile wastewaters [138], or to identify for the first time the molecular structure of LAS anaerobic degradation metabolites [139], although due to their high cost and relatively lower sensitivity compared with HPLC-MS-MS they are not often used for routine analysis of these compounds in environmental samples.

Table 5 provides general information about some analytical procedures aimed to the determination of surfactants in different environmental matrices by HPLC-MS (and some other detectors). So far, LAS and SPCs have been determined in both freshwater [71] and marine environments [40] using several kinds of MS detectors coupled to HPLC under negative ion (NI) mode due to the presence of a sulfonate group. Quasi-molecular ions $[\mathrm{M}-\mathrm{H}]^{-}$ and a characteristic fragment $\mathrm{m} / \mathrm{z}=183$ were used for their identification and quantification. AES have also been monitored in aquatic systems $[62,140]$ in a similar way, but $\mathrm{m} / \mathrm{z}=97$, corresponding to $\mathrm{HO}-\mathrm{SO}_{3}{ }^{-}$, was selected as the main fragment ion. On the other hand, identification of QACs relies upon measurement of their molecular ions $\left(\mathrm{M}^{+}\right)$in positive ionization mode (PI), and further confirmation can be achieved by mass measurement of main characteristic ions such as $\mathrm{m} / \mathrm{z}=60$ for alkyltrimethylammonium chlorides (ATACs) [141] or $\mathrm{m} / \mathrm{z}=91$ for BACs [94]. Non-ionic surfactants lack charge or acid/base functional groups, so the most widely used option for ionization of ethoxylated compounds, such as NPEOs and AEOs, is to form adducts as the oxygen atoms in the polyethoxylate chain can donate their free electrons to a selected cation agent and the flexible structure of the chain 


\begin{tabular}{|c|c|c|c|c|c|c|c|c|}
\hline $\begin{array}{c}\text { Target } \\
\text { analytes }\end{array}$ & Matrix & $\begin{array}{l}\text { Sample } \\
\text { treatment }\end{array}$ & $\begin{array}{c}\text { Recovery } \\
\text { (\%) }\end{array}$ & Mobile phase & Column & Detection & $\begin{array}{l}\text { LOD/ } \\
\text { MLD }\end{array}$ & Ref \\
\hline $\begin{array}{c}\text { BAC, } \\
\text { DADMA } \\
\text { C }\end{array}$ & $\begin{array}{l}\text { Marine } \\
\text { sediment }\end{array}$ & $\begin{array}{l}\text { Sonication, } \\
\text { LLE, SPE }\end{array}$ & $\begin{array}{c}\text { 98-118 } \\
\text { (DADMA } \\
\text { C) }\end{array}$ & $\begin{array}{c}\mathrm{ACN} / \mathrm{H}_{2} \mathrm{O}, \\
\text { isopropanol, } \\
\mathrm{FA}, \mathrm{AMAC}\end{array}$ & $\begin{array}{c}\text { Luna C18 } \\
(150 \mathrm{~mm}, \\
2 \mathrm{~mm}, 5 \mu \mathrm{m})\end{array}$ & $\begin{array}{l}\text { ESI(+)- } \\
\text { ToF-MS }\end{array}$ & $\begin{array}{c}0.1-2.6 \\
\mathrm{ng} / \mathrm{g} \\
(\mathrm{LOQ})\end{array}$ & [65] \\
\hline LAS, SPC & $\begin{array}{c}\text { Seawater, } \\
\text { marine } \\
\text { sediment }\end{array}$ & Soxhlet, SPE & $75-105$ & $\begin{array}{c}\mathrm{MeOH} / \mathrm{H}_{2} \mathrm{O} \\
\mathrm{H}_{2} \mathrm{O}_{\text {, }} \\
\text { tetraethyl } \\
\text { ammonium } \\
\text { hydrogensulfa } \\
\text { te }\end{array}$ & $\begin{array}{l}\text { LiChrosorb } \\
\text { RP-8 (250 } \\
\mathrm{mm}, \quad 4.6 \\
\mathrm{~mm}, \\
10.6 \mu \mathrm{m})\end{array}$ & FL & $\begin{array}{c}0.2-0.4 \\
\mu \mathrm{g} / \mathrm{L} \\
5-10 \\
\mu \mathrm{g} / \mathrm{Kg}\end{array}$ & [52] \\
\hline $\begin{array}{c}\text { NPEO, } \\
\text { NP }\end{array}$ & $\begin{array}{c}\text { Marine } \\
\text { sediment, } \\
\text { sewage }\end{array}$ & $\begin{array}{l}\text { Sonication, } \\
\text { SPE } \\
\text { LLE }\end{array}$ & $\begin{array}{c}\text { 64-127 } \\
\text { (sediment) }\end{array}$ & $\begin{array}{c}\mathrm{H}_{2} \mathrm{O}, \mathrm{MeOH}, \\
\text { sodium } \\
\text { acetate }\end{array}$ & $\begin{array}{l}\text { MSpak GF- } \\
3104 \mathrm{D} \\
\text { filtration } \\
\text { column } \\
(150 \mathrm{~mm}, \\
4.6 \mathrm{~mm})\end{array}$ & $\begin{array}{l}\text { ESI-MS } \\
\text { NPEO } \\
\text { (ESI+) } \\
\text { NP (ESI-) }\end{array}$ & $\begin{array}{l}0.78- \\
37.3 \\
n g / g\end{array}$ & [127] \\
\hline $\begin{array}{c}\text { LAS, } \\
\text { SPC, } \\
\text { NPEO, } \\
\text { NP1-2EC, } \\
\text { AEO, } \\
\text { PEG }\end{array}$ & $\begin{array}{l}\text { Sewage, } \\
\text { marine } \\
\text { sediment, } \\
\text { seawater, } \\
\text { s. solids }\end{array}$ & $\begin{array}{l}\text { Sonication, } \\
\text { SPE }\end{array}$ & $\begin{array}{c}\text { 26-117 } \\
\text { (AEOs, } \\
\text { PEGs) } \\
60-108 \\
\text { (NPEOs, } \\
\text { NP1-2EC) } \\
37-101 \\
\text { (LAS, SPC) }\end{array}$ & $\begin{array}{l}\mathrm{ACN}, \mathrm{H}_{2} \mathrm{O}, \\
\text { FA, } \\
\text { ammonium } \\
\text { formate }\end{array}$ & $\begin{array}{c}\text { Luna C18 } \\
(150 \mathrm{~mm}, \\
2 \mathrm{~mm}, 5 \mu \mathrm{m})\end{array}$ & $\begin{array}{c}\text { ESI-ToF- } \\
\text { MS } \\
\text { LAS, SPC, } \\
\text { NP1-2EC } \\
\text { (ESI-) } \\
\text { NPEO, } \\
\text { AEO } \\
(\text { ESI+) }\end{array}$ & $\begin{array}{c}0.1-11.8 \\
\mathrm{ng} / \mathrm{L} \\
0.1-23.7 \\
\mu \mathrm{g} / \mathrm{Kg}\end{array}$ & [40] \\
\hline $\begin{array}{c}\text { AEO, } \\
\mathrm{NP}_{1-3 \mathrm{EO}}, \\
\mathrm{NP}, \\
\mathrm{NP}_{1-2 \mathrm{EC}}\end{array}$ & $\begin{array}{c}\text { Marine } \\
\text { sediment }\end{array}$ & $\begin{array}{c}\text { Sonication, } \\
\text { SPE }\end{array}$ & 34-88 & $\begin{array}{l}\mathrm{ACN}, \mathrm{H}_{2} \mathrm{O}, \\
\text { FA, } \\
\text { ammonium } \\
\text { formate }\end{array}$ & $\begin{array}{l}\text { Purospher } \\
\text { STAR RP-18 } \\
\text { UHPLC } \\
\text { column (50 } \\
\mathrm{mm}, 2 \mathrm{~mm} \text {, } \\
1.8 \mu \mathrm{m})\end{array}$ & $\begin{array}{l}\text { ESI(+)- } \\
\text { MS-MS }\end{array}$ & $\begin{array}{l}<0.1- \\
27.3 \\
\mathrm{ng} / \mathrm{g}\end{array}$ & [44] \\
\hline $\begin{array}{c}\text { BAC, } \\
\text { ATAC, } \\
\text { DADMA } \\
\text { C }\end{array}$ & $\begin{array}{l}\text { River } \\
\text { sediment, } \\
\text { sludge }\end{array}$ & $\begin{array}{l}\text { Soxhlet, } \\
\text { LLE }\end{array}$ & $67-95$ & $\begin{array}{c}\mathrm{ACN} / \mathrm{H}_{2} \mathrm{O}, \\
\text { isopropanol, } \\
\mathrm{FA}, \mathrm{AMAC}\end{array}$ & $\begin{array}{c}\text { Luna C18 } \\
(150 \mathrm{~mm}, \\
2 \mathrm{~mm}, 5 \mu \mathrm{m})\end{array}$ & $\begin{array}{l}\text { ESI(+)- } \\
\text { MS-MS }\end{array}$ & $\begin{array}{c}0.6-5 \\
\mu \mathrm{g} / \mathrm{Kg} \\
\text { (LOQ) }\end{array}$ & [27] \\
\hline QAC & $\begin{array}{l}\text { River } \\
\text { water, } \\
\text { sewage }\end{array}$ & $\begin{array}{l}\text { Microporou } \\
\text { s } \\
\text { membrane } \\
\text { liquid- } \\
\text { liquid } \\
\text { extraction }\end{array}$ & - & $\begin{array}{l}\text { Chloroform, } \\
\text { ethanol, } \\
\text { ammonia, } \\
\text { heptanoic acid }\end{array}$ & $\begin{array}{l}\text { Cyanopropyl } \\
\text { column (250 } \\
\mathrm{mm}, 2 \mathrm{~mm})\end{array}$ & UV & $\begin{array}{l}0.7-5 \\
\mu \mathrm{g} / \mathrm{L}\end{array}$ & [101] \\
\hline
\end{tabular}

Table 5. Key aspects of HPLC analysis of surfactants in different environmental matrices. 
allows the molecule to "wrap" itself around that cation [64]. Thus, sodium acetate [60, 74], ammonium acetate $[89,142]$ or different acids [53] are commonly added to the samples or to the mobile phase to increase the MS response of NPEOs and AEOs and to stabilize the generation of $[\mathrm{M}+\mathrm{Na}]^{+},\left[\mathrm{M}+\mathrm{NH}_{4}\right]^{+}$or $[\mathrm{M}+\mathrm{H}]^{+}$ions, among others. Additionally, this ability to form different adducts can be used to obtain multiple confirmation points in full-scan mode [40]. Another advantage of MS compared to other detectors is that several types of surfactants can be analyzed within a single run (e.g., NPEOs and AEOs can be separated, using an adequate gradient, and later analyzed under PI [53, 64]). Most recent methodologies allow simultaneous determination of anionic and non-ionic surfactants and their metabolites in environmental samples $[47,55]$.

Today, mass spectrometry is often combined with ultra-performance liquid chromatography (UPLC), which uses sub-2- $\mu \mathrm{m}$ column particles that provide enhanced separation, faster analysis, and improved sensitivity over HPLC, boosting laboratory efficiency by saving time and decreasing solvent consumption. Most researchers have started to benefit from this combination, although there are still a few examples on its use for analysis of surfactants. So far, UPLC-Q-ToF-MS has been used for structural elucidation of SPC isomers [139] and for environmental screening of several anionic and non-ionic surfactants in wastewater [138]. UPLC-MS-MS [44] has allowed achieving fast analysis (less than 10 min per sample) of NPEO metabolites and AEOs at trace levels in aquatic environments.

\section{Conclusion}

The assessment of the behavior and final fate of synthetic surfactants in the environment is a crucial matter due to the huge volumes of these chemicals that are discharged into aquatic and terrestrial ecosystems. A significant number of analytical protocols have been developed over the last decades aimed to the individual or simultaneous extraction, isolation and determination of different types of surfactants in environmental samples. Nowadays, the most widely used sample preparation protocols are based on SPE, directly derived from column chromatography. However, the trend is to research on new techniques, such as SPME or SBSE, aimed to reduce, or even eliminate, solvent consumption, as well as saving money by using reusable fibers and bars rather than disposable cartridges. Regarding the separation, identification and quantification of surfactants, HPLC-MS and, to a lesser extent due to the non volatility of most analytes, GCMS, are the main tools currently employed as they allow for determination of every single homologue, ethoxymer and/or isomer from surfactant mixtures in different environmental matrices (solids, water and biota). Most recently, different classes of time-of-flight and triple quadrupole mass spectrometers have started to be combined with UPLC, which provides enhanced separation, faster analysis, higher confidence, and lower detection limits than more conventional HPLC-MS or HPLC-MS-MS approaches, as well as improves identification of unknown surfactant metabolites and other non target compounds within the same run. 


\section{List of abbreviations}

AA, Acetic acid; ASE, Accelerated solvent extraction; ACN, Acetonitrile; AEOs, Alcohol polyethoxylates; AES, Alkyl ethoxysulfates; AS, Alkyl sulfates; ATACs, Alkyltrimethylammonium chlorides; AP, Alkylphenol; APEOs, Alkylphenol polyethoxylates; APEC, Alkylphenol polyethoxycarboxylate; AMAC, Ammonium acetate; APCI, Atmospheric pressure ionization; BACs, Benzalkonium chlorides; BSTFA, N,Obis(trimethylsilyl)trifluoro acetamide; CWAX/TR, Carbowax/template resin; CI, Chemical ionization; DTDMAC, Dehydrogenated tallow dimethyl ammonium chloride; DADMAC, Dialkyldimethylammonium chlorides; DCM, Dichloromethane; DLLME, Dispersive liquidliquid microextraction; EI, Electron impact ionization; ESI, Electrospray ionization; EO, Ethylene oxide; CESIO, European Committee of Organic Surfactants and their Intermediates; FID, Flame-ionization detectors; FIA, Flow-injection analysis; FL, Fluorescence detectors; FA, Formic acid; GC, Gas chromatography; GBC, Graphitized black carbon; HPLC, High-performance liquid chromatography; HLB, Hydrophilic-lipophilic balance; LOD, Limit of detection; LOQ, Limit of quantification; LAS, Linear alkylbenzene sulfonates; LC, Liquid chromatography; LLE, Liquid-liquid extraction; MS, Mass spectrometry; MSPD, Matrix solid-phase dispersion; MeOH, Methanol; MLD, Method limit detection; MAE, Microwave-assisted extraction; NC, Naphthyl chloride; NI, Negative ionization; NP, Nonylphenol; NPEOs, Nonylphenol polyethoxylates; NPECs, Nonylphenol polyethoxycarboxylates; OP, Octylphenol; OPEOs, Octylphenol polyethoxylates; PA, Polyacrylate; PEGs, Polyethylenglycols; SDB, Polystyrene-divinylbezene; PDMS/DVB, Polydimethylsiloxane/divinylbenzene; PI, Positive ionization; PT, Potentiometric titrametration; PFE, Pressurized fluid extraction; PLE, Pressurized liquid extraction; Q-ToF, Quadrupole time-of-flight; QACs, Quaternary ammonium-based compounds; SIM, Selected ion monitoring; SDS, Sodium dodecyl sulphate; SLE, Solid-liquid extraction; SPE, Solid phase extraction; SPME, Solid phase microextraction; SBSE, Stir-bar sorptive extraction; SAX, Strong anionic-exchange; SCX, Strong cationic-exchange; SPCs, Sulfophenyl carboxylic acids; SFE, Supercritical fluid extraction; MS-MS, Tandem mass spectrometry; ToF, Time-offlight; UPLC, Ultra performance liquid chromatography; UV, Ultraviolet detectors; WWTPs, Wastewater treatment plants.

\section{Author details}

Juan M. Traverso-Soto, Eduardo González-Mazo and Pablo A. Lara-Martín Departamento de Química Física, Facultad de Ciencias del Mar y Ambientales, Campus de Excelencia Internacional del Mar (CEI·MAR), Universidad de Cádiz, Puerto Real, Spain

\section{References}

[1] Thiele B (2005) Analysis of Surfactants in Samples of the Aquatic Environment. In: L.M.L. Nollet, editor. Chromatographic Analysis of the Environment. Boca Raton: CRC Press. pp. 1173-1198. 
[2] Ying G.G (2006) Fate, behavior and effects of surfactants and their degradation products in the environment. Environ. Int. 32: 417-431.

[3] Environmental Risk Assesment (2009) Linear Alkylbenzene Sulfonate (LAS). In: Human and Environmental Risk Assesment on Ingredients of European Household Cleaning Products. Brussels.

[4] Environmental Risk Assesment (2004) Alcohol Ethoxysulfates (AES). In: Human and Environmental Risk Assesment on Ingredients of European Household Cleaning Products. Brussels.

[5] Environmental Risk Assesment (2002) Alkyl Sulfates. In: Human and Environmental Risk Assesment on Ingredients of European Household Cleaning Products. Brussels.

[6] Jobling S.J, Sumpter J.P (1993) Detergent components in sewage effluent are weakly oestrogenic to fish: An in vitro study using rainbow trout (Oncorhynchus mykiss) hepatocytes. Aquat. Toxicol. 27: 361-72.

[7] Purdom C.E, Hardiman P.A, Bye V.V.J, Eno N.C, Tyler C.R, Sumpter J.P (1994) Estrogenic Effects of Effluents from Sewage Treatment Works. Chem. Ecol. 8: 275-85.

[8] Sonnenschein C., Soto A.M (1998) An Updated Review of Environmental Estrogen and Androgen Mimics and Antagonists. J. Steroid Biochem. Molec. Biol. 65: 143-150.

[9] Human and Environmental Risk Assesment (2009) Alcohol Ethoxylates (AEOs). In: Human and Environmental Risk Assesment on Ingredients of European Household Cleaning Products. Brussels.

[10] Madsen T, Buchardt Boyd H, Nylén D, Rathmann Pedersen A, Petersen G.I, Simonsen F (2001) Environmental and Health Assessment of Substances in Household Detergents and Cosmetic Detergent Products. In: Environmental Project No. 615, Miljøprojekt. Danish Environmental Protection Agency.

[11] Berenbold H (1994) Rinse Softeners-current situation in Europe. International News on Fats, Oils and Related Materials 5(1): 82-84.

[12] Giolando S.T, Rapaport R.A, Larson R.J, Federle T.W, Stalmans M, Masscheleyn P (1995) Environmental fate and effects of DEEDMAC: a new rapidly biodegradable cationic surfactant for use in fabric softeners. Chemosphere 30(6): 1067- 83.

[13] Environmental Risk Assesment (2008) Esterquats. In: Human and Environmental Risk Assesment on Ingredients of European Household Cleaning Products. Brussels.

[14] Berna J.L, Ferrer J, Moreno A, Prats D, Ruiz Bevia F (1989) The fate of LAS in the environment. Tenside Surf. Det. 26: 101-107.

[15] Prats D, Ruiz F, Vazquez B, Rodríguez-Pastor M (1997) Removal of Anionic and Nonionic Surfactants in a Wastewater Treatment Plant with Anaerobic Digestion. A Comparative Study. Wat. Res. 31: 1925-1930.

[16] González S, Petrovic M, Barceló D (2004) Simultaneous extraction and fate of linear alkylbenzene sulfonates, coconut diethanol amides, nonylphenol ethoxylates and their degradation products in wastewater treatment plants, receiving coastal waters and sediments in the Catalonian area (NE Spain). J. Chromatogr. A 1052: 111-120.

[17] Morrall S.W, Dunphy J.C, Cano M.L, Evans A, McAvoy D.C, Price B.P, Eckhoff W.S (2006) Removal and environmental exposure of alcohol ethoxylates in US sewage treatment. Ecotoxicol. Environ. Saf. 64: 3-13. 
[18] Clara M, Scharf S, Scheffknecht C, Gans O (2007) Ocurrence of selected surfactants in untreated and treated sewage. Water Res. 41: 4339-4348.

[19] Sanderson H, Dyer S.D, Price B.B, Nielsen A.M, van Compernolle R, Selby M, Stanton K, Evans A, Ciarlo M, Sedlak R (2006) Ocurrence and weight-of-evidencce risk assessment of alkyl sulfates, alkyl ethoxysulfates, and linear alkylbenzene sulfonates (LAS) in river water and sediments. Sci. Total Environ. 368: 695-712.

[20] Kreuzinger N, Fuerhacker M, Scharf S, Uhl M, Gans O, Grillitsch B (2007) Methodological approach towards the environmental significance of uncharacterized substances - quaternary ammonium compounds as an example. Desalination 215: 209222.

[21] Eadsforth C.V, Sherren A.J, Selby M.A, Toy R, Eckhoff W.S, McAvoy D.C, Matthijs E (2006) Monitoring of environmental fingerprints of alcohol ethoxylates in Europe and Canada. Ecotoxicol. Environ. Saf. 64: 14-29.

[22] Loyo-Rosales J.E, Rice C.P, Torrents A (2007) Octyl and nonylphenol ethoxylates and carboxylates in wastewater and sediments by liquid chromatography/tandem mass spectrometry. Chemosphere 68: 2118-2127.

[23] Cavalli L, Gellera A, Landone A (1993) LAS removal and biodegradation in a wastewater treatment plant. Environ. Toxicol. Chem. 12: 1777-1788.

[24] Ahel M, Giger W, Koch M (1994) Behaviour of Alkylphenol Polyethoxylate Surfactants in the Aquatic Environment-I. Ocurrence and Transformation in Sewage Treatment. Wat. Res. 28: 1131-1142.

[25] Bruno F, Curini R, Di Corcia A, Fochi I, Nazzari M, Samperi R (2002) Determination of surfactants and some of their metabolites in untreated and anaerobically digested sewage sludge by subcritical water extraction followed by liquid chromatography-mass spectrometry. Environ. Sci. Technol. 36:4156- 61.

[26] Fernandez P, Alder A.C, Suter M.J.F, Giger W (1996) Determination of the Quaternary Ammonium Surfactant Ditallowdimethylammonium in Digested Sludges and Marine Sediments by Supercritical Fluid Extraction and Liquid Chromatography with Postcolumn Ion-Pair Formation. Anal. Chem. 68: 921-9.

[27] Martínez-Carballo E, González-Barreiro C, Sitka A, Kreuzinger N, Scharf S, Gans O (2007) Determination of selected quaternary ammonium compounds by liquid chromatography with mass spectrometry. Part II. Application to sediment and sludge samples in Austria. Environ. Pollut. 146: 543-547.

[28] Holt M.S (2000) Sources of Chemical Contaminants and Routes into the Freshwater Environment. Food Chem. Toxicol. 38: S21-S27.

[29] Ding W.H, Tzing Shin-Haw, Lo Jun-Hui (1999) Ocurrence and Concentrations of Aromatic Surfactants and their Degradation Products in River Waters of Taiwan. Chemosphere 38: 2597-2606.

[30] Marcomini A, Pojana G, Sfriso A, Quiroga Alonso José-Maria (2000) Behavior of Anionic and Nonionic Surfactants and their Persistent Metabolites in the Venice Lagoon, Italy. Environ. Toxicol. Chem. 19: 2000-2007. 
[31] Corada-Fernández C, Lara-Martín P.A, Candela L, González-Mazo E (2011) Tracking sewage derived contamination in riverine settings by analysis of synthetic surfactants. J. Environ. Monit. 13: 2010.

[32] Belmont M.A, Ikonomou M, Metcalfe C.D (2006) Presence of nonylphenol ethoxylate surfactants in a watershed in central Mexico and removal from domestic sewage in a treatment wetland. Environ. Toxicol. Chem. 25: 29-35.

[33] Jonkers N, Laane R.W.P.M, de Voogt P (2003) Fate of nonylphenol ethoxylates and their metabolites in two Dutch estuaries: evidence of biodegradation in the field. Environ. Sci. Technol. 37: 321-327.

[34] Maruyama K, Yuan M, Otsuki A (2000) Seasonal changes in ethylene oxide chain length of poly(oxyethylene)alkylphenyl ether nonionic surfactants in three main rivers in Tokyo. Environ. Sci. Technol. 34: 343-348.

[35] Lee Ferguson P, Iden C.R, Brownawell B.J (2001) Distribution and fate of neutral alkylphenol ethoxylate metabolites in a sewage-impacted urban estuary. Environ. Sci. Technol. 35: 2428-2435.

[36] Petrovic M, Rodríguez Fernández-Alba A, Borrull F, Marce R.M, González-Mazo E., Barceló D (2002) Ocurrence and Distribution of Nonionic Surfactants, their Degradation Products, and Linear Alkylbenzene Sulfonates in Coastal Waters and Sediments in Spain,. Environ. Toxicol. Chem. 21: 37-46.

[37] Zoller U (2006) Estuarine and coastal zone marine pollution by the nonionic alkylphenol ethoxylates endocrine disrupters: Is there a potential ecotoxicological problem? Environ. Int. 32: 269-272.

[38] Lara-Martín P.A, Petrovic M, Gómez-Parra A, Barceló D, González-Mazo E (2006) Presence of surfactants and their degradation intermediates in sediment cores and grabs from the Cadiz Bay area. Environ. Pollut. 144: 483-491.

[39] León V.M, Sáez M, González-Mazo E., Gómez-Parra A (2002) Ocurrence and distribution of linear alkylbenzene sulfonates and sulfophenylcarboxylic acids in several Iberian littoral ecosystems. Sci. Total Environ. 288: 215-226.

[40] Lara-Martín P.A, González-Mazo E, Brownawell B.J (2011) Multi-residue method for the analysis of synthetic surfactants and their degradation metabolites in aquatic systems by liquid chromatography-time-of-flight-mass spectrometry. J. Chromatogr. A 1218: 4799-4807.

[41] Bester K, Theobald N, Schröder H.Fr (2001) Nonylphenols, nonylphenol-ethoxylates, linear alkylbenzenesulfonates (LAS) and bis (4-chlorophenyl)-sulfone in the German Bight of the North Sea. Chemosphere 45: 817-826.

[42] Isobe T, Takada H (2004) Determination of degradation products of alkylphenol polyethoxylates in municipal wastewaters and rivers in Tokyo. Japan. Environ. Toxicol. Chem. 23: 599-605.

[43] Lara-Martín P.A, Gómez-Parra A, González-Mazo E (2008) Sources, transport and reactivity of anionic and non-ionic surfactants in several aquatic ecosystems in SW Spain: A comparative study. Environ. Pollut. 156: 36-45.

[44] Lara-Martín P.A, González-Mazo E, Brownawell B.J (2011) Enviromental analysis of alcohol ethoxylates and nonylphenol ethoxylate metabolites by ultra-performance 
liquid chromatography-tandem mass spectrometry. Anal. Bioanal. Chem. DOI: 10.1007/s00216-011-5449-6.

[45] Lara-Martín P.A, Li X, Bopp R.F, Brownawell B.J (2010) Ocurrence of Alkyltrimethylammonium Compounds in Urban Estuarine Sediments: Behentrimonium As a New Emerging Contaminant. Environ. Sci. Technol. 44: 75697575 .

[46] Li X, Brownawell B.J (2010) Quaternary Ammonium Compounds in Urban Estuarine Sediment Environments - A Class of Contaminants in Need of Increased Attention?. Environ. Sci. Technol. 44: 7561-7568.

[47] Lara-Martín P.A, Gómez-Parra A, González-Mazo E (2006) Development of a method for the simultaneous analysis of anionic and non-ionic surfactants and their carboxylated metabolites in environmental samples by mixed-mode liquid chromatography-mass spectrometry. J. Chromatogr. A 1137: 188-197.

[48] Krogh K.A, Mogensen B.B, Halling-Sorensen B, Cortés A, Vejrup K.V, Barceló D (2003) Analysis of alcohol ethoxylates and alkylamine ethoxylates in agricultural soils using pressurized liquid extraction and liquid chromatography-mass spectrometry. Anal. Bioanal. Chem. 376: 1089-1097.

[49] Jonkers N, Laane R.W.P.M, de Voogt P (2005) Sources and fate of nonylphenol ethoxylates and their metabolites in the Dutch coastal zone of the North Sea. Mar. Chem. 96: 115-135.

[50] Selberg A, Budashova J, Tenno T (2007) Column study of the leaching and degradation of anionic surfactants in oil-polluted soil. Proc. Estonian Acad. Sci. Chem. 56: 87-97.

[51] Shang D.Y, Ikonomou M.G, Macdonald R.W (1999) Quantitative determination of nonylphenol polyethoxylate surfactants in marine sediment using normal-phase liquid chromatography-electrospray mass spectrometry. J. Chromatogr. A 849: 467-482.

[52] León V.M, González-Mazo E, Gómez-Parra A (2000) Handling of marine and estuarine samples for the determination of linear alkylbenzene sulfonates and sulfophenylcarboxylic acids. J. Chromatogr. A 889: 211-219.

[53] Jeannot R, Sabik H, Sauvard E, Dagnac T, Dohrendorf K (2002) Determination of endocrine-disrupting compounds in environmental samples using gas and liquid chromatography with mass spectrometry. J Chromatogr. A 974: 143-159.

[54] Sablayrolles C, Montréjaud-Vignoles M, Silvestre J, Treilhou M (2009) Trace Determination of Linear Alkylbenzene Sulfonates: Application in Artificially Polluted Soil-Carrots System. Int. J. Anal. Chem. 2009: 1-6.

[55] Petrovic M, Barceló D (2000) Determination of Anionic and Nonionic Surfactants, Their Degradation Products, and Endocrine-Disrupting Compounds in Sewage Sludge by Liquid Chromatography/Mass Spectrometry. Anal. Chem. 72: 4560-4567.

[56] Sun H.F , Takata A, Hata N, Kasahara I, Taguchi S (2003) Transportation and fate of cationic surfactant in river water. J. Environ. Monit. 5: 891-895.

[57] Holt M.S, Bernstein S.L (1992) Linear Alkylbenzenes in Sewage Sludges and Sludge Amended Soils. Wat. Res. 26: 613-624. 
[58] Reiser R, Toljander H.O, Giger W (1997) Determination of Alkylbenzenesulfonates in Recent Sediments by Gas Chromatography/Mass Spectrometry. Anal. Chem. 69: 49234930.

[59] Li D, Oh Jae-Ryoung, Park J (2003) Direct extraction of alkylphenols, chlorophenols and bisphenol A from acid-digested sediment suspension for simultaneous gas chromatographic-mass spectrometric analysis. J. Chromatogr. A 1012: 207-214.

[60] Lee Ferguson P, Iden C.R, Brownawell B.J (2000) Analysis of Alkylphenol Ethoxylate Metabolites in the Aquatic Environment Using Liquid Chromatography-Electrospray Mass Spectrometry. Anal. Chem. 72: 4322-4330.

[61] Bennie D.T, Sullivan C.A, Lee H.-B, Peart T.E, Maguire R.J (1997) Ocurrence of alkylphenols and alkylphenol mono- and diethoxylates in natural waters of the Laurentian Great Lakes basin and the upper St. Lawrence River. Sci. Tot. Environ. 193: 263-275.

[62] Lara-Martín P.A, Gómez-Parra A, González-Mazo E (2006) Simultaneous extraction and determination of anionic surfactants in waters and sediments. J. Chromatogr. A 1114: 205-210.

[63] Chiron S, Sauvard E, Jeannot R (2000) Determination of nonionic polyethoxylate surfactants in wastewater and sludge samples of sewage treatment plants by liquid chromatography-mass spectrometry. Analusis 28: 535-542.

[64] Cohen A, Klint K, Bøwadt S, Persson P, Jönsson J.A (2001) Routine analysis of alcohol and nonylphenol polyethoxylates in wastewater and sludge using liquid chromatography-electrospray mass spectrometry. J. Chromatogr. A 927: 103-110.

[65] Li X, Brownawell B.J (2009) Analysis of Quaternary Ammonium Compounds in Estuarine Sediments by LC-ToF-MS: Very High Positive Mass Defects of Alkylamine Ions as Powerful Diagnostic Tools for Identification and Structural Elucidation. Anal. Chem. 81: 7926-7935.

[66] Villar M, Callejon M, Jimenez J.C, Alonso E, Guiraum A (2007) Optimization and validation of a new method for analysis of linear alkylbenzene sulfonates in sewage sludge by liquid chromatography after microwave-assisted extraction. Anal. Chim. Acta 599: 92-97.

[67] Bartolomé L, Cortazar E, Raposo J.C, Usobiaga A, Zuloaga O, Etxebarria N, Fernandez L.A (2005) Simultaneous microwave-assisted extraction of polycyclic aromatic hydrocarbons, polychlorinated biphenyls, phthalate esters and nonylphenols in sediments. J. Chromatogr. A 1068: 229-236.

[68] Croce V, Patrolecco L, Polesello S, Valsecchi S (2003) Extraction of Nonylphenol and Nonylphenol Ethoxylates from River Sediments: Comparison of Different Extraction Techniques. Chromatographia 58: 145-149.

[69] Stuart J.D, Capulong C.P, Launer K.D, Pan X (2005) Analysis of phenolic endocrine disrupting chemicals in marine samples by both gas and liquid chromatography-mass spectrometry. J. Chromatogr. A 1079: 136-145.

[70] Morales-Muñoz S, Luque-García J.L, Luque de Castro M.D (2004) Screening method for linear alkylbenzene sulfonates in sediments based on water Soxhlet extraction assisted 
by focused microwaves with on-line preconcentration/derivatization/detection. J. Chromatogr. A 1026: 41-46.

[71] Eichhorn P, López O, Barceló D (2005) Application of liquid chromatographyelectrospray-tandem mass spectrometry for the identification and characterization of linear alkylbenzene sulfonates and sulfophenyl carboxylates in sludge-amended soils. J. Chromatogr. A 1067: 171-179.

[72] Ferrer I, Furlong E.T (2002) Accelerated Solvent Extraction Followed by On-Line SolidPhase Extraction Coupled to Ion Trap LC/MS/MS for Analysis of Benzalkonium Chlorides in Sediment Samples. Anal. Chem. 74: 1275-1280.

[73] Loyo-Rosales J.E, Schmitz-Afonso I, Rice C.P, Torrents A (2003) Analysis of Octyl- and Nonylphenol and Their Ethoxylates in Water and Sediments by Liquid Chromatography/Tandem Mass Spectrometry. Anal. Chem. 75: 4811-4817.

[74] Petrovic M, Lacorte S, Viana P, Barceló D (2002) Pressurized liquid extraction followed by liquid chromatography-mass spectrometry for the determination of alkylphenolic compounds in river sediment. J. Chromatogr. A 959: 15-23.

[75] Field J.A, Miller D.J, Field T.M, Hawthorne S.B, Giger W (1992) Quantitative Determination of Sulfonated Aliphatic and Aromatic Surfactants in Sewage Sludge by Ion-Pair/Supercritical Fluid Extraction and Derivatization Gas Chromatography/Mass Spectrometry. Anal. Chem. 64: 3161-3167.

[76] Field J.A, Reed R.L (1999) Subcritical (Hot) Water/Ethanol Extraction of Nonylphenol Polyethoxy Carboxylates from Industrial and Municipal Sludges. Environ. Sci. Technol. 33: 2782-2787.

[77] Breen D.G.P.A, Horner J.M, Bartle K.D, Clifford A.A, Waters J, Lawrence J.G (1996) Supercritical Fluid Extraction and Off-Line HPLC Analysis of Cationic Surfactants from Dried Sewage Sludge. Wat. Res. 30: 476-480.

[78] Jurado E, Fernández-Serrano M, Núñez-Olea J, Luzón G, Lechuga M (2006) Simplified spectrophotometric method using methylene blue for determining anionic surfactants: Applications to the study of primary biodegradation in aerobic screening tests. Chemosphere 65: 278-285.

[79] Roslan R.N, Hanif N.M, Othman M.R, Azmi W.N.F.W, Yan X.X, Ali M.M, Mohamed C.A.R, Latif M.T (2010) Surfactants in the sea-surface microlayer and their contribution to atmospheric aerosols around coastal areas of the Malaysian peninsula. Mar. Poll. Bull. 60: 1584-1590.

[80] Nagarnaik P.M, Mills M.A, Boulanger B (2010) Concentrations and mass loadings of hormones, alkylphenols, and alkylphenol ethoxylates in healthcare facility wastewaters. Chemosphere 78: 1056-1062.

[81] Wyrwas B, Szymanski A, Lukaszewski Z (1998) Tensammetric determination of nonionic surfactants combined with the BiAS separation procedure Part 3. Determination in the presence of hydrocarbons. Talanta 47: 325-333.

[82] Idouhar M, Tazerouti A (2008) Spectrophotometric Determination of Cationic Surfactants Using Patent Blue V: Application to the Wastewater Industry in Algiers. J. Surfact. Deterg. 11: 263-267. 
[83] Koga M, Yamamichi Y, Nomoto Y, Irie M, Tanimura T, Yoshinaga T (1999) Rapid Determination of Anionic Surfactants by Improved Spectrophotometric Method Using Methylene Blue. Anal. Sci. 15: 563-568.

[84] Akyüz M (2007) Ion-pair extraction and GC-MS determination of linear alkylbenzene sulphonates in aqueous environmental samples. Talanta 71: 471-478.

[85] Matthijs E, Holt M.S, Kiewiet A, Rijs G.B.J (1999) Environmental Monitoring for Linear Alkylbenzene Sulfonate, Alcohol Ethoxylate, Alcohol Ethoxy Sulfate, Alcohol Sulfate, and Soap. Environ. Toxicol. Chem. 18: 2634-2644.

[86] Crescenzi C, Di Corcia A, Marchiori E, Samperi R, Marcomini A (1996) Simultaneous Determination of Alkylbenzenesulfonates and Dialkyltetralinsulfonates in Water by Liquid Chromatography. Wat. Res. 30: 722-730.

[87] Bruzzoniti M.C, De Carlo R.M, Sarzanini C (2008) Determination of sulfonic acids and alkylsulfates by ion chromatography in water. Talanta 75: 734-739.

[88] Pojana G, Cassani G, Marcomini A (2004) Determination, aerobic biodegradation and environmental occurrence of aliphatic alcohol polyethoxylate sulfates (AES). Int. J. Environ. Anal. Chem. 84: 729-738.

[89] Houde F, DeBlois C, Berryman D (2002) Liquid chromatographic-tandem mass spectrometric determination of nonylphenol polyethoxylates and nonylphenol carboxylic acids in surface water. J. Chromatogr. A 961: 245-256.

[90] Fendinger N.J, Begley W.M, McAvoy D.C, Eckhoff W.S (1995) Measurement of Alkyl Ethoxylate Surfactants in Natural Waters. Environ. Sci. Technol. 29: 856-863.

[91] Petrovic M, Díaz A, Ventura F, Barceló D (2001) Simultaneous Determination of Halogenated Derivatives of Alkylphenol Ethoxylates and Their Metabolites in Sludges, River Sediments, and Surface, Drinking, and Wastewaters by Liquid ChromatographyMass Spectrometry. Anal. Chem. 73: 5886-5895.

[92] Dunphy J.C, Pessler D.G, Morrall S.W (2001) Derivatization LC/MS for the Simultaneous Determination of Fatty Alcohol and Alcohol Ethoxylate Surfactants in Water and Wastewater Samples. Environ. Sci. Technol. 35: 1223-1230.

[93] Cassani G, Tibaldi F, Donato G, Andriollo N (2011) Determination of Alcohol Ethoxylates derivatized with Napthoyl Chloride, in Waste Water Treatment Plant Influent, Effluent and Sludge Samples by Liquid Chromatography Mass Spectrometry. J. Surfact. Deterg. 14: 139-150.

[94] Merino F, Rubio S, Pérez-Bendito D (2003) Solid-Phase Extraction of Amphiphiles Based on Mixed Hemimicelle/Admicelle Formation: Application to the Concentration of Benzalkonium Surfactants in Sewage and River Water. Anal. Chem. 75: 6799-6806.

[95] Merino F, Rubio S, Pérez-Bendito D (2004) Evaluation and Optimization of an On-Line Admicelle-Based Extraction-Liquid Chromatography Approach for the Analysis of Ionic Organic Compounds. Anal. Chem. 76: 3878-3886.

[96] Bassarab P, Williams D, Dean J.R, Ludkin E, Perry J.J (2011) Determination of quaternary ammonium compounds in seawater samples by solid-phase extraction and liquid chromatography-mass spectrometry. J. Chromatogr. A 1218: 673-677. 
[97] Autry J.K, Vaught E.G, Conte E.D (2005) Preconcentration of bezalkonium chloride using sodium dodecyl sulfate attached to a strong anion exchange resin. Microchem. J. 80: 25-29.

[98] Luque N, Merino F, Rubio S, Pérez-Bendito D (2005) Stability of benzalkonium surfactants on hemimicelle-based solid-phase extraction cartridges. J. Chromatogr. A 1094: 17-23.

[99] Tolls J, Haller M, Sijm D.T.H.M (1999) Extraction and Isolation of Linear Alkylbenzenesulfonate and Its Sulfophenylcarboxylic Acid Metabolites from Fish Samples. Anal. Chem. 71: 5242-5247.

[100] Zgoła-Grzéskowiak A, Kaczorek E (2011) Isolation, preconcentration and determination of rhamnolipids in aqueous samples by dispersive liquid-liquid microextraction and liquid chromatography with tandem mass spectrometry. Talanta 83: 744-750.

[101] Norberg J, Thordarson E, Mathiasson L, Jönsson J.A (2000) Microporous membrane liquid-liquid extraction coupled on-line with normal-phase liquid chromatography for the determination of cationic surfactants in river and waste water. J. Chromatogr. A 869: 523-529.

[102] Hultgren S, Larsson N, Nilsson B.F, Jönsson J.A (2009) Ion-pair hollow-fiber liquidphase microextraction of the quaternary ammonium surfactant dicocodimethylammonium chloride. Anal. Bioanal. Chem. 393: 929-937.

[103] Luo S, Fang L, Wang X, Liu H, Ouyang G, Lan C, Luan T (2010) Determination of octylphenol and nonylphenol in aqueous sample using simultaneous derivatization and dispersive liquid-liquid microextraction followed by gas chromatography-mass spectrometry. J. Chromatogr. A 1217: 6762-6768.

[104] Bidari A, Ganjali M.R, Norouzi P (2010) Development and evaluation of a dispersive liquid-liquid microextraction based test method for quantitation of total anionic surfactants: advantages against reference methods. Cent. Eur. J. Chem. 8: 702-708.

[105] Alzaga R, Peña A, Ortiz L, Bayona J.M (2003) Determination of linear alkylbenzensulfonates in aqueous matrices by ion-pair solid-phase microextraction-inport derivatization-gas chromatography-mass spectrometry. J. Chromatogr. A 999: 5160.

[106] Rico-Rico A, Droge S.T.J, Widmer D, Hermens J.L.M (2009) Freely dissolved concentrations of anionic surfactants in seawater solutions: Optimization of the nondepletive solid-phase microextraction method and application to linear alkylbenzene sulfonates. J. Chromatogr. A 1216: 2996-3002.

[107] Boyd-Boland A.A, Pawliszyn J.B (1996) Solid-Phase Microextraction Coupled with High-Performance Liquid Chromatography for the Determination of Alkylphenol Ethoxylate Surfactants in Water. Anal. Chem. 68: 1521-1529.

[108] Pan Y.-P, Tsai S.-W (2008) Solid phase microextraction procedure for the determination of alkylphenols in water by on-fiber derivatization with N-tert-butyl-dimethylsilyl-Nmethyltrifluoroacetamide. Anal. Chim. Acta 624: 247-252.

[109] Kawaguchi M, Sakui N, Okanouchi N, Ito R, Saito K, Nakazawa H (2005) Stir bar sorptive extraction and trace analysis of alkylphenols in water samples by thermal 
desorption with in tube silylation and gas chromatography-mass spectrometry. J. Chromatogr. A 1062: 23-29.

[110] Coll C, Martínez-Máñez R, Marcos M.D, Sancenón F, Soto J (2007) A Simple Approach for the Selective and Sensitive Colorimetric Detection of Anionic Surfactants in Water. Angew. Chem. Int. Ed. 46: 1675-1678.

[111] Coll C, Ros-Lis J.V, Martínez-Máñez R, Marcos M.D, Sancenón F, Soto J (2010) A new approach for the selective and sensitive colorimetric detection of ionic surfactants in water. J. Mater. Chem. 20: 1442-1451.

[112] Ródenas-Torralba E, Reis B.F, Morales-Rubio A, de la Guardia M (2005) An environmentally friendly multicommutated alternative to the reference method for anionic surfactant determination in water. Talanta 66: 591-599.

[113] Khaled E, Mohamed G.G, Awad T (2008) Disposal screen-printed carbon paste electrodes for the potentiometric titration of surfactants. Sens. Actuators B 135: 74-80.

[114] Szymanski A, Wyrwas B, Jesiołowska A, Kazmierczak S, Przybysz T, Grodecka J, Łukaszewski Z (2001) Surfactants in the River Warta: 1990-2000. Pol. J. Environ. Stud. 10: 371-377.

[115] Yokoyama Y, Okabe T, Kubo H, Sato H (2005) Spectrophotometric Determination of Polyoxyethylene Nonionic Surfactants in Ground Waters Using Triple-Stage SolidPhase Extraction Followed by an Improved Ferric Thiocyanate Complexation Method. Microchim. Acta 149: 287-293.

[116] Bas B, Jakubowska M (2007) Estimation of non-ionic, surface-active substances in aqueous solutions by means of the Controlled Growth Mercury Electrode. Anal. Chim. Acta 592: 218-225.

[117] Li S, Zhao S (2004) Spectrophotometric determination of cationic surfactants with benzothiaxolyldiazoaminoazobenzene. Anal. Chim. Acta 501: 99-102.

[118] Yamamoto K, Oka M, Murakami H (2002) Spectrophotometric determination of trace ionic and non-ionic surfactants based on a collection on a membrane filter as the ion associate of the surfactant with Erythrosine B. Anal. Chim. Acta 455: 83-92.

[119] Zhu Z, Li Z, Hao Z, Chen J (2003) Direct spectrophotometric determination of alkylphenol polyethoxylate nonionic surfactants in wastewater. Wat. Res. 37: 4506-4512.

[120] Szymanski A, Wyrwas B, Szymanowska M, Lukaszewski Z (2001) Determination of Short-Chained Poly(ethyleneglycols) and Ethylene Glycol in Environmental Samples. Wat. Res. 35: 3599-3604.

[121] Lizondo-Sabater J, Martínez-Máñez R, Sancenón F, Seguí M.J, Soto J (2008) Ionselective electrodes for anionic surfactants using a cyclam derivative as ionophore. Talanta 75: 317-325.

[122] Jiménez-Díaz I, Ballesteros O, Zafra-Gómez A, Crovetto G, Vílchez J.L, Navalón A, Verge C, de Ferrer J.A (2010) New sample treatment for the determination of alkylphenols and alkylphenol ethoxylates in agricultural soils. Chemosphere 80: 248255.

[123] Moldovan Z, Avram V, Marincas O, Petrov P, Ternes T (2011) The determination of the linear alkylbenzene sulfonate isomers in water samples by gas-chromatography/mass spectrometry. J. Chromatogr. A 1218: 343-349. 
[124] McEvoy J, Giger W (1986) Determination of Linear Alkylbenzenesulfonates in Sewage Sludge by High-Resolution Gas Chromatography/Mass Spectrometry. Environ. Sci. Technol. 20: 376-383.

[125] Hibberd A, Maskaoui K, Zhang Z, Zhou J.L (2009) An improved method for the simultaneous analysis of phenolic and steroidal estrogens in water and sediment. Talanta 77: 1315-1321.

[126] Ahel M, Giger W (1985) Determination of Alkylphenols and Alkylphenol Mono- and Diethoxylates in Environmental Samples by High-Performance Liquid Chromatography. Anal. Chem. 57: 1577-1583.

[127] Lee Ferguson P, Iden C.R, Brownawell B.J (2001) Analysis of nonylphenol and nonylphenol ethoxylates in environmental samples by mixed-mode high-performance liquid chromatography-electrospray mass spectrometry. J. Chromatogr. A 938: 79-91.

[128] Olkowska E, Polkowska Z, Namiesnik J (2012) Analytical procedures for the determination of surfactants in environmental samples. Talanta 88: 1-13.

[129] Cantarero S, Zafra-Gómez A, Ballesteros O, Navalón A, Vílchez J.L, Verge C, De Ferrer J.A (2011) Matrix Effect Study in the Determination of Linear Alkylbenzene Sulfonates in Sewage Sludge Samples. Environ. Toxicol. Chem. 30: 813-818.

[130] Cortazar E, Bartolomé L, Delgado A, Etxebarria N, Fernández L.A, Usobiaga A, Zuloaga $\mathrm{O}$ (2005) Optimisation of microwave-assisted extraction for the determination of nonylphenols and phthalate esters in sediment samples and comparison with pressurized solvent extraction. Anal. Chim. Acta 534: 247-254.

[131] Nakae A, Tsuji K, Yamanaka M (1980) Determination of Trace Amounts of Alkylbenzenesulfonates by High-Performance Liquid Chromatography with Fluorimetric Detection. Anal. Chem. 52: 2275-2277.

[132] Kiewiet A.T, van der Steen J.M.D, Parsons J.R (1995) Trace Analysis of Ethoxylated Nonionic Surfactants in Samples of Influent and Effluent of Sewage Treatment Plants by High-Performance Liquid Chromatography. Anal. Chem. 67: 4409-4415.

[133] Zanette M, Marcomini A, Marchiori E, Samperi R (1996) High-performance liquid chromatographic-fluorescence determination of aliphatic alcohol polyethoxylates and polye(thylene glycol)s in aqueous samples. J. Chromatogr. A 756: 159-174.

[134] Schröder H.F (2001) Tracing of surfactants in the biological wastewater treatment process and the identification of their metabolites by flow injection-mass spectrometry and liquid chromatography-mass spectrometry and -tandem mass spectrometry. J. Chromatogr. A 926: 127-150.

[135] Jhanke A, Gandrass J, Ruck W (2004) Simultaneous determination of alkylphenol ethoxylates and their biotransformation products by liquid chromatography/electrospray ionization tandem mass spectrometry. J. Chromatogr. A 1035: 115-122.

[136] Lunar L, Rubio S, Pérez-Bendito D (2004) Differentation and quantification of linear alkyl benzenesulfonate isomers by liquid chromatography-ion-trap mass spectrometry. J. Chromatogr. A 1031: 17-25. 
[137] Bernhard M, Eubeler J.P, Zok S, Knepper T.P (2008) Aerobic biodegradation of polyethylene glycols of different molecular weights in wastewater and seawater. Wat. Res. 42: 4791-4801.

[138] González S, Petrovic M, Radetic M, Jovancic P, Ilic V, Barceló D (2008) Characterization and quantitative analysis of surfactants in textile wastewater by liquid chromatography/quadrupole-time-of-flight mass spectrometry. Rapid Commun. Mass Spectrom. 22: 1445-1454.

[139] Lara-Martín P.A, Gómez-Parra A, Sanz J.L, González-Mazo E (2010) Anaerobic Degradation Pathway of Linear Alkylbenzene Sulfonates (LAS) in Sulfate-Reducing Marine Sediments. Environ. Sci. Technol. 44: 1670-1676.

[140] Krogh K.A, Vejrup K.V, Mogensen B.B, Halling-Sørensen B (2002) Liquidchromatography-mass spectrometry method to determine alcohol ethoxylates and alkylamine ethoxylates in soil interstitial water, ground water and surface water samples. J. Chromatogr. A 957: 45-57.

[141] Martínez-Carballo E, Sitka A, González-Barreiro C, Kreuzinger N, Fürhacker M, Scharf S, Gans O (2007) Determination of selected quaternary ammonium compounds by liquid chromatography with mass spectrometry. Part I. Application to surface, waste and indirect discharge water samples in Austria. Environ. Pollut. 145: 489-496.

[142] Droge S.T.J, Sinnige T.L, Hermens J.L.M (2007) Analysis of Freely Dissolved Alcohol Ethoxylate Homologues in Various Seawater Matrixes Using Solid-Phase Microextraction. Anal. Chem. 79: 2885-2891.

[143] Ding W.-H, Tzing S.-H (1998) Analysis of nonylphenol polyethoxylates and their degradation products in river water and sewage effluent by gas chromatography-ion trap (tandem) mass spectrometry with electron impact and chemical ionization. J. Chromatogr. 824: 79-90.

[144] Ding W.-H, Lo J.-H, Tzing S.-H (1998) Determination of linear alkylbenzenesulfonates and their degradation products in water samples by gas chromatography with ion-trap mass spectrometry. J. Chromatogr. A 818: 270-279. 